REVESCO. Revista de Estudios Cooperativos

ISSN: $1885-8031$

\title{
Economía Social y Economía Solidaria: un análisis bibliométrico y revisión de literatura
}

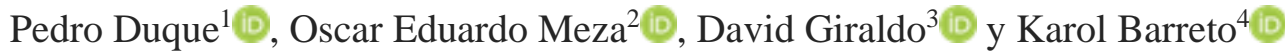

Recibido: 30 de noviembre de 2020 / Aceptado: 1 de abril de 2021 / Publicado: 14 de junio de 2021

Resumen. La economía social y la economía solidaria han representado desde finales del siglo XX un modelo económico alternativo y en constante evolución, orientado a generar beneficios con criterios de impacto social, abordando problemáticas como la desigualdad, la democratización de los recursos y la primacía en las personas antes que el capital. Debido al creciente interés y relevancia del tema en la actualidad, este estudio pretende contribuir al conocimiento de esta área, a partir de un análisis y revisión de la literatura registrada en las bases de datos WoS y Scopus entre los años 2000 y 2020, empleando métodos y herramientas bibliométricas. Mediante un mapeo científico se identificaron los principales enfoques, escuelas, autores, revistas, países e instituciones en este campo; además, se clasificaron los documentos más relevantes, en tres categorías, clásicos, estructurales y perspectivas, los cuales fueron representados a través de la metáfora del árbol de la ciencia. También, se determinaron los principales frentes de investigación recientes en el área, como emprendimientos sociales, desarrollo de comunidades y sostenibilidad, y la economía social en países emergentes. Finalmente, se propone una agenda para futuros estudios.

Palabras clave: Crisis económica; Impacto social; Desarrollo económico; Capitalismo; Tercer sector.

Claves Econlit: B55; L31; M14.

\section{[en] Social Economy and Solidarity Economy: a bibliometric analysis and literature review}

Abstract. Since the end of the 20th century, the social economy and the solidarity economy have represented an alternative economic model in constant evolution, aimed at generating profits with social impact criteria, addressing inequality, the democratization of resources, and the primacy of people over the capital. Due to the growing interest and relevance of the topic, this study aims to contribute to the knowledge of this area, based on an analysis and review of the literature registered in the WoS and Scopus databases between 2000 and 2020, using bibliometric methods and tools. The main approaches, schools, authors, journals, countries, and institutions in this field were identified from a scientific mapping. The most relevant documents were classified into three categories, classical, structural, and perspectives, represented through the metaphor of the tree of science. The main research fronts in the area, social entrepreneurship, community development and sustainability, and social economy in emerging countries, were determined. Finally, an agenda for future studies.

Keywords: Economic crisis; Social impact; Social inequality; Economic development; Capitalism; Third sector.

Sumario. 1. Introducción. 2. Metodología. 3. Desarrollo del análisis bibliométrico. 4. Conclusiones. 5. Referencias bibliográficas.

Cómo citar. Duque, P.; Meza, O.E.; Giraldo, D.; Barreto, K. (2021) Economía Social y Economía Solidaria: un análisis bibliométrico y revisión de literatura. REVESCO. Revista de Estudios Cooperativos, vol. 138, e75566. https://dx.doi.org/10.5209/reve.75566.

\section{Introducción}

En un contexto de crisis mundial, desencadenada por la propagación de la pandemia covid-19, que ha agudizado las profundas desigualdades socioeconómicas en el mundo (Hudson, 2020), se han incrementado las manifestaciones de índole social, como expresión de repudio al capitalismo que le rinde tributo al

1 Universidad Católica Luis Amigó, Manizales, Colombia.

Dirección de correo electrónico: pedro.duquehu@amigo.edu.co.

2 Universidad Nacional de Colombia, Manizales, Colombia.

Dirección de correo electrónico: oscar.mezaag@amigo.edu.co.

Universidad Católica Luis Amigó, Manizales, Colombia.

Dirección de correo electrónico: jose.giraldoas@ amigo.edu.co.

4 Universidad Católica Luis Amigó, Manizales, Colombia.

Dirección de correo electrónico: karol.barretogo@amigo.edu.co 
mercado (Kenworthy, 2020), señalando las asimetrías socioeconómicas imperantes y exigiendo una recomposición de las políticas económicas que han venido imperando en la sociedad mundial en el último siglo (Presta, 2020). Lo anterior, demuestra que la gestión social que enmarca el capitalismo es completamente asimétrica, que con el paso del tiempo son más evidentes (Kazeroony, 2014). Esta situación, ha generado un espacio paulatino para las prácticas socioeconómicas, orientadas en lo denominado como economía social y economía solidaria, soportadas en el propósito comunitario y equitativo como una alternativa sostenible para propiciar comportamientos organizacionales diferentes (Guadarrama, 2019).

Las organizaciones de economía social y economía solidaria, cuya finalidad es aportar en la construcción de una sociedad equitativa, atraen cada vez más la atención de las comunidades de todo el mundo, relacionándose con nuevas perspectivas emergentes que se conforman como una alternativa a los modelos de organización tradicionales (Kim et al., 2020). Diferentes actores sociales como investigadores, académicos, responsables gubernamentales de la política económica y social, empresarios y profesionales de diferentes disciplinas de todo el mundo, tienen sus ojos puestos en este campo, por su potencial para enfrentar temas de las problemáticas sociales como la desigualdad, el desempleo y la pobreza (Chaves y Demoustier, 2013).

Tanto la economía solidaria como la economía social, en la actualidad juegan un papel importante para algo trascendental para el mundo, como lo es el desarrollo sostenible (Li et al., 2020), incluso es un tema innovador para los actuales gobiernos, quienes desde la contratación pública pueden transformar la forma de convenir este ejercicio fundamental, convirtiéndolos en instrumentos idóneos para alcanzar los objetivos sociales, económicos y ambientales que plantean los enfoques de sostenibilidad (Arce, 2020).

A pesar de la importancia del tema, aún se encuentra en construcción y consolidación, por lo cual se requiere una revisión de literatura que aporte en este sentido, abordando su evolución, además, que permita identificar los autores, países, publicaciones, las revistas que mayor impacto tienen en el área, y las corrientes o perspectivas de investigación que emergen en los últimos años. Así mismo, se identificaron algunos trabajos que presentan cierta relación con el objeto de estudio. Por ejemplo, Botelho, Wuerges y Schneider (2015) realizaron una revisión bibliográfica sistemática integral donde establecieron cómo se articulan los temas de tecnología Social, economía social e incubadoras tecno-sociales de cooperativas populares en la literatura nacional de Brasil. Marier et al. (2017) determinaron a través de una revisión de literatura, los principales problemas de control a los que se enfrentan los directivos de proyectos de organizaciones de economía social y solidaria. Rey et al. (2016), realizan un análisis de revisión bibliométrica sobre emprendimiento social, donde identifican los principales autores, países, idiomas, revistas y áreas de investigación sobre este campo en auge.

De acuerdo a lo anterior, con el fin de aportar en este ámbito de estudio, el presente artículo desarrolla una revisión sistemática de literatura sobre la economía social y economía solidaria, mediante la aplicación de herramientas y técnicas bibliométricas. En el cumplimiento de este objetivo, se realizó la consulta del tema empleando las bases de datos Web of Science (WoS) y Scopus con un rango de tiempo del año 2000 al 2020. Los resultados fueron tratados y procesados a través de la herramienta $\mathrm{R}$, de esta manera, realizar el estudio bibliométrico, posteriormente, por medio de un análisis de red, se clasificaron los trabajos más relevantes en área, para ello, se empleó la metáfora del árbol, la cual, los categoriza en tres grupos; raíz, tronco y hojas, identificando así, las corrientes emergentes de investigación en el área. Finalmente, se realiza un análisis de los documentos principales en cada categoría.

El presente artículo está dividido en cuatro secciones principales; la primera esboza la metodología empleada para la búsqueda, selección, verificación y análisis de los artículos con los respectivos criterios de búsqueda en referencia al objeto de estudio. En la segunda, se realiza un análisis de origen y referente teórico sobre economía social y economía solidaria. En la tercera, se realiza el análisis bibliométrico y de redes. En la cuarta y última sección, se presentan las conclusiones, limitaciones y la agenda para futuras investigaciones en torno al tema de economía solidaria y social.

\section{Metodología}

El proceso metodológico llevado a cabo en esta investigación se encuentra desarrollado en dos fases. La primera, es un mapeo científico del área, a través de un análisis bibliométrico de la producción científica registrada en WoS y Scopus, y la segunda, un análisis de red que permite identificar los documentos más relevantes sobre economía social y economía solidaria, además, de establecer los principales grupos en los que se enmarcan en la actualidad las investigaciones en el área.

\subsection{Mapeo Científico}

Con el fin de realizar un análisis de producción y mapeo científico, se utilizan los cinco métodos bibliométricos sugeridos por Zupic y Čater (2015): análisis de citaciones, análisis de coocurrencia de palabras, análisis de cocitaciones, análisis de coautorías y análisis de acoplamiento bibliográfico. Se 
emplearon de forma conjunta en WoS y Scopus, ya que permite tener un panorama más amplio del área de conocimiento (Echchakoui, 2020), además estas dos bases de datos son consideradas como las principales a nivel mundial (Bar-Ilan, 2008; Zhu y Liu, 2020). Los parámetros de búsqueda se relacionan en la Tabla 1.

Tabla. 1. Parámetros de Búsqueda.

\begin{tabular}{|c|c|}
\hline Bases de datos & Web of Science \\
\hline Periodo de consulta en años & $2000-2020$ \\
\hline Fecha de consulta & Enero 2, 2021 \\
\hline Tipo de documento & Artículo, libro, capítulo de libro, documento de conferencia \\
\hline Tipo de revista & Todos los tipos \\
\hline Campos de búsqueda & $\begin{array}{l}\text { Título } \\
\end{array}$ \\
\hline Términos de búsqueda & $\begin{array}{l}\text { "économie sociale" or "économie solidaire" or "économie sociale et } \\
\text { solidaire" or "solidarity economy" or "social economy" or "social and } \\
\text { solidarity economy" or "economia social" or "economia solidaria" or } \\
\text { "economia social y solidaria" }\end{array}$ \\
\hline Resultados & 797 \\
\hline Resultado total & 1297 \\
\hline
\end{tabular}

Fuente: Elaboración propia (2021)

Estos criterios de búsqueda arrojaron 696 registros en WoS y 797 en Scopus, que fusionados y después de la eliminación de los datos duplicados, se consolidaron como 1297, lo que representa una superposición del $14 \%$ entre estas dos bases de datos, demostrando la pertinencia de usarlas de forma conjunta. Al involucrar en los parámetros de búsqueda los términos economía social y economía solidaria en diferentes idiomas (francés, inglés y español), se pretende abarcar la mayor cantidad de registros al interior de estas bases de datos. Como resultado, se identifica que el 55\% de las publicaciones en esta área, relacionadas en WoS y Scopus se encuentran en idioma Inglés, mientras que en Español y Francés, el 22\% y $7 \%$ respectivamente (Figura 1). Esto se debe a que el inglés es el idioma dominante en estas bases de datos, además, estas revistas y autores procuran realizar sus publicaciones en este idioma para aumentar su visibilidad (Vera et al., 2019).

La herramienta utilizada para el análisis bibliométrico es Bibliometrix (Aria y Cuccurullo, 2017), ya que es una herramienta de uso libre, que permite trabajar con diferentes bases de datos y sus funcionalidades son múltiples, además, ha sido empleada y validada por otros estudios (Aria et al., 2020; Bond et al., 2019; Demiroz y Haase, 2019; Duque et al., 2020; Tani et al., 2018).

Figura. 1. Idiomas.

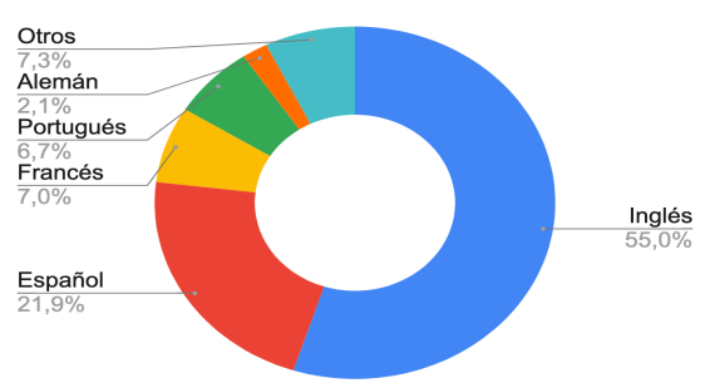

Fuente: Elaboración propia (2021)

\subsection{Análisis de Red}

Los registros obtenidos en WoS y Scopus fueron fusionados y eliminados los duplicados, para ello se empleó programación en el Software R, luego se extraen sus referencias (bibliografía) y se estructura una red de citaciones empleando como modelo la teoría de grafos, esta última, es una técnica que facilita generar información sobre la tipología y características de la red, así mismo, de todos los documentos que la componen (Wallis, 2007; Yang et al., 2016).

Posteriormente, se calculan tres indicadores bibliométricos: el Indegree (número de veces que un documento ha sido referenciado por otros), el Outdegree (número de veces que un nodo en particular cita a otros o número de conexiones de cada documento) según (Wallis, 2007); y el Betweenness que es grado de 
intermediación y centralidad de cada elemento dentro de la red (Freeman, 1977), este último indicador, presenta cuando el documento es referenciado y referencia a los demás (Zhang y Luo, 2017).

El resultado final, es la red de conocimiento de esta área, constituida por todos los documentos obtenidos de las bases de datos y de sus respectivas referencias, lo que implica que se involucran trabajos de múltiples fuentes, no solo los que hacen parte de WoS y Scopus, también de otras bases de datos y publicaciones científicas. Este análisis de redes, o también conocido como mapa de cocitaciones, permite la visualización de la estructura de un área de conocimiento, además, facilita la identificación de sus subáreas o corrientes de investigación (Gurzki y Woisetschläger, 2017; Zuschke, 2020). Para facilitar la visualización gráfica de la red de conocimiento del área de estudio sobre economía social y economía solidaria, se emplea la herramienta Gephi (Bastian et al., 2009).

A cada uno de los registros de la red, se le calculan los indicadores indegree, outdegree y betweenness, los cuales, permiten clasificar los trabajos empleando la metáfora del árbol (Robledo et al., 2014; Valencia et al., 2020). Teniendo en cuenta esta analogía, surgen tres categorías: Las raíces (alto indegree), donde se observan los documentos clásicos y de relevancia hegemónica teórica dentro del campo de estudio, en especial contempla publicaciones que son citadas pero no citan a otros (Wallis, 2007). Luego está el tronco (alto betweenness), allí se ubican documentos que citan pero al mismo tiempo son citados por los demás (Zhang y Luo, 2017), en este componente se agrupan los trabajos estructurales, los cuales conectan la fundamentación teórica de los clásicos, con las investigaciones actuales. Por último, las hojas (alto outdegree), se focaliza en los documentos más recientes, y que citan los demás (Wallis, 2007), estos trabajos muestran las tendencias actuales en las que se enmarcan las investigaciones en el área, constituyéndose como los frentes de investigación emergentes. Este procedimiento metodológico ha sido empleado y validado en estudios previos (Buitrago et al., 2020; Duque et al., 2020, 2021; Duque y Cervantes, 2019; Hernandez et al., 2020; Salazar et al., 2020).

\subsection{Origen y referente teórico sobre la Economía Social y la Economía Solidaria}

Es creciente el interés sobre el estudio de la economía social y su campo de acción, en especial por parte de la comunidad científica en Europa, Norteamérica y Latinoamérica, además, de organizaciones públicas y de entes internacionales como las Naciones Unidas, la Organización de Estados Americanos, la Comisión Europea, la Organización para la Cooperación y el Desarrollo Económico y la Organización Internacional del Trabajo (Chaves y Demoustier, 2013), resaltan la importancia de este campo y motivan el interés del presente artículo, el cual, aborda los fundamentos y principales planteamientos de autores, que dieron origen y desarrollo a la economía social y a la economía solidaria, especialmente en los países europeos más representativos y en la locución de Estados Unidos y los países latinoamericanos.

Se identifican a nivel mundial múltiples organizaciones caracterizadas por los principios de asociatividad, cooperación, solidaridad, autogestión, reciprocidad y democracia, que se enmarcan en figuras jurídicas y normadas por entes centrales de acuerdo a las denominaciones y campo de acción específico en cada país (Davila et al., 2018). Según Pestoff y Stryjan (2008) las entidades de economía social son determinadas por el contexto social, político y cultural circundante, y en algunos casos, son reguladas por diferentes estándares, por ejemplo, en países nórdicos como Suecia y Dinamarca, las cooperativas están alienadas con el desarrollo movimientos de participación social, el compromiso cívico y el fomento de la igualdad y la democracia. En España y Francia es categorizada como la economía social y el tercer sector; en Noruega es considerada como el sector voluntario; en ciertos países de Asia se identifica como economía social, sector de cooperación y sistema intermediario; en cuanto a algunos países de áfrica es denominado como sector cooperativo o sector caritativo, mientras que en Australia se llama sector filantrópico. Respecto a países latinoamericanos se presentan diversas locuciones, como economía popular en Ecuador, economía informal en Perú, economía del trabajo en Argentina, Economía Solidaria y Tercer Sector en Brasil y Economía Solidaria en Colombia. Las diversas connotaciones y enfoques divergentes que presenta el concepto de economía social y economía solidaria en las diferentes regiones, evidencian un debate permanente por parte de académicos, investigadores, líderes políticos, directivos e instituciones de acuerdo a los principios y fines que representan estas organizaciones, siendo necesario abordar a continuación algunos de sus planteamientos más representativos.

Se identifican los contextos de crisis como un catalizador para consolidar la economía social, denominada por algunos autores, como el tercer sector, debido a que está situada entre las organizaciones públicas y el sector privado tradicional (Labrador et al., 2017); destacando que la denominación como tercer sector fue adoptada inicialmente en Estados Unidos por Levitt (1973), en relación al sector que impulsa las actividades micro y macroeconómicas que corrigen los desequilibrios económicos y sociales del mercado, y que ya han sido objeto de estudio por parte de la comunidad académica (Defourny, 1992; Stiglitz, 2009; Tomás, 1997).

Pérez y Etxezarreta (2015) plantean que el concepto de economía social, contempla un consenso de principios e institucionalidad aceptado por la comunidad científica y por el marco legal en diferentes países (Bouchard, 2009; Fajardo, 2012; Monzón, 2013), pero que en contraste el concepto de economía solidaria 
presenta criterios en construcción y debate (Coraggio, 2013). Complementan este campo de estudio, nuevas publicaciones que proyectan la economía social como una iniciativa que gestiona armónicamente los recursos naturales, el bienestar comunitario y la calidad de vida, con el objetivo de impactar en la transformación del modelo de desarrollo económico convencional a partir del impacto positivo en la dimensión social (Abad, 2019; Fernández et al., 2020; Villalba y Pérez, 2019).

En el mismo sentido Battisti et al. (2020), sugieren que se articulan en algunos casos la economía social con la economía solidaria en un mismo propósito y principios, pero en otros se establece una diferenciación y complementaria entre los dos conceptos. En este campo de análisis se identifican publicaciones de diferentes autores; por ejemplo França Filho (2002) que plantea una delimitación de sus significados; también, Laville (2004) expone la necesidad de abordar de manera exhaustiva su conceptualización, aduciendo que mientras la economía solidaria es carácter filantrópico, la economía social presenta una solidaridad de carácter democrático; así mismo, Da Ros (2007) aborda la orientación y diferenciación teórica de la economía solidaria desarrollada en europa y la latinoamericana; Guerra (2007) expone a partir de autores los diferentes enfoques emergentes en algunos países, desde la orientación en principios solidarios y asociativos; y, de Mendiguren y Etxarri (2015) analizan de una perspectiva teórica y empírica el uso del concepto híbrido de Economía Social y Solidaria. Por otro lado, González (2018), plantea la necesidad de separar el sector solidario de la economía social y solidaria estableciendo criterios diferenciales de integración económica, expresión y orientación política y cultural.

Resaltando la participación ciudadana voluntaria y la colaboración con socios públicos, requiere que la economía solidaria sea comprendida como la forma de democratizar la economía y no como el resurgimiento de la filantropía (Chanial y Laville, 2002). En síntesis, y según la definición planteada por Lipietz, mientras la economía social responde a la pregunta "¿cómo hacerlo?", en referencia a estatutos y reglas de funcionamiento, lo que definiría a la economía solidaria sería "¿en nombre de qué se hace?”, en referencia a valores, sentido de la acción y criterios de gestión (Castelao, 2016).

A continuación se abordan los enfoques más representativos y hegemónicos en lo que se refiere a la construcción conceptual del campo denominado como economía social y economía solidaria, específicamente en países identificados como el origen de los movimientos que fundamentan su objeto de estudio.

\subsubsection{Francia: Économie Sociale}

Según McIntyre (2018), las bases de la economía social, se identifican por movimientos franceses del siglo XIX, y se le atribuye a Charles Dunoyer el término, especialmente a partir de la revolución industrial con el impulso de autores como SaintSimon, Fourier, Proudhon y Blanc, en conjunto los planteamientos de economistas de renombre como Leon Walras en su obra "Études d'économie sociale: théorie de la répartition de la richesse sociale", quien plantea la integración formal de los trabajadores, a través de figuras cooperativas y mutualistas. Luego Chaves y Monzón (2018), reafirman la importancia del enfoque francés, exponiendo que a finales de la década del setenta, las figuras asociativas, mutuales y cooperativas conformaron una organización para unificar sus propósitos. Creando el CNLAMCA (Battisti et al., 2020), Comité National de Liaison des Activités Coopératives, mutuelles et associatves, que posteriormente publicaría en 1980 la Charte de léconomie sociale, donde se conceptualiza la economía social como entidades no pertenecientes al sector público que, con funcionamiento y gestión democrática e igualdad de derechos y deberes de los socios, practican un régimen especial de propiedad y distribución de las ganancias, empleando los excedentes del ejercicio para el crecimiento de la entidad y la mejora de los servicios a los socios y a la sociedad" (Davila et al., 2018; Périz, 2002).

En una línea conceptual similar, compartiendo la convergencia francófona, se establece en 1990 en Bélgica, que la economía social comprende principios como, desarrollar servicios para sus socios antes que buscar el lucro, garantizar la democracia, primar la distribución de excedentes en las personas antes que al capital, e independientes del sector público y privado tradicional. A partir de 1980, el concepto de economía solidaria en Francia articuló tres elementos; las demandas sociales, los actores y el deseo de un cambio social. Sobre la base de que la economía es plural por naturaleza y representa un intento de unir las economías de mercado, de no mercado y no monetarias (Fajardo, 2011). Entre la multiplicidad de autores franceses en este campo, se destaca el investigador contemporáneo Jean Louis Laville, que tiene como marco referencial los planteamientos de Karl Polanyi (Davila et al, 2018), a partir del concepto de economía plural, recíproca y redistributiva (França Filho y Laville, 2004), complementando su perspectiva con la connotación socioeconómica y sociopolítica de la economía solidaria, que se articula con los planteamientos en este campo de investigadores como Eric Dacheux y Daniel Goujon (2018).

Diversos autores en los últimos años han contribuido a la construcción y planteamientos sobre la economía social y la economía solidaria en Francia, con posturas convergentes en algunos conceptos y principios, pero divergentes en otros, lo cual fortalece el debate académico e investigativo, algunos de ellos son Jean François Draperi, Danièle Demoustier, Jacques Defourny, Jean Louis Laville, François Legendre, 
Jérôme Blanc, Thierry Jeantet, Marguerite Mendell, Klein, J.L., Nyssens, M., Zafirovski, M., Fontan, J.M., Huybrechts, B., Moulaert, F., y Archambault, E., entre otros. Además, desde 1979 está conformada la Association d'Économie Sociale que se identifica como una organización que promueve la producción y difusión de trabajos de investigación en Economía Social anualmente, y que tiene como red de aliados a la Revue Internationale de l'économie Sociale,_Association Française de Science Économique y Revue Française de Socio-Économie. Esta red y gran parte de los autores franceses citados se identifican con los principios de justicia social, cooperación, adhesión libre, igualdad, prioridad sobre la comunidad y la solidaridad, sin tener como fin principal el lucro, sostenibilidad con el entorno y la democracia de las organizaciones, representadas principalmente por cooperativas, asociaciones y mutuales que buscan conciliar la actividad económica con la equidad social. En síntesis, abordar el enfoque de la economía social en Francia es cuestionar los modos de producción, consumo y políticas públicas desde criterios que le den respuesta efectiva a la justicia social, la democracia, la igualdad y la ciudadanía como fin principal, representadas principalmente en sus inicios por cooperativas y mutuales de carácter privado.

\subsubsection{Estados Unidos: Social Economy}

Paralelo al contexto vivido en países europeos, en los años 70 se estaba presentando una situación coyuntural crítica en la economía de los Estados Unidos, surgiendo una locución sobre la importancia de la economía solidaria, representada por las entidades del Sector No Lucrativo (Nonprofit Organizations), denominación establecida por Weisbrod en la década del ochenta según Monzón (2006). Estableciendo como principales objetivos, su estructura institucional, su carácter privado, autogobernadas, con excedentes reinvertidos en su función principal, y con plena participación voluntaria (Salamon y Anheier, 1997).

El enfoque para categorizar y caracterizar principalmente estas entidades como no lucrativas, es predominantemente en Estados Unidos (Chaves et al., 2013; Davila et al., 2018) o de su equivalente britanico denominado como Voluntary Sector (Monzón, 2006); que a su vez está relacionado con locuciones filantrópicas, benéficas y voluntarias, donde los posibles excedentes de la entidad se asignan nuevamente a su objeto social y no a sus miembros o fundadores (Powell y Steinberg, 2006; Weisbrod, 2009). Con base a los aportes de la Universidad Johns Hopkins, en la década del noventa se consolidó la identidad de las organizaciones sin fines de lucro, como 'nonprofit', estableciendo los principios que las caracterizan (Salamon y Anheier, 1997). Los cuales se pueden resumir en organizaciones que poseen estructura institucional, de carácter privado, autónomas, de participación voluntaria y que no reparten beneficios y por lo tanto deben ser reinvertidos en la misión principal, denominadas por ende como sin ánimo de lucro y siendo esta la característica diferencial predominante del enfoque anglosajón con los enfoques de países de europa, como Francia, España y Alemania. Este tipo de organizaciones, tradicionalmente adoptan la formalidad jurídica de asociaciones y fundaciones, con una gestión contable y tributaria diferenciada en Estados Unidos; además las Naciones Unidas han publicado con el apoyo de la universidad Johns Hopkins, un manual sobre las instituciones sin ánimo de lucro en el sistema de cuentas nacionales. En esta misma orientación Chaves y Monzón (2018), destacan los aportes de Hansmann (1980) y Weisbrod (1986). Sin embargo, considerar como único criterio, que las entidades sin ánimo de lucro pertenecen al sector de economía social, es bastante complejo y limitado, según lo expuesto por Alam et al. (2018), debido a algunas aproximaciones y posibles confusiones del sector con las ONG.

Es importante resaltar que desde 1941, la Association for Social Economics se fundó con el fin de formar una red de académicos, investigadores y profesionales que a través de la reflexión ética y social conciban el comportamiento económico, mediante una relación recíproca, pluralista y orientada a la dignidad humana por encima del ánimo de lucrarse. Se destacan como espacios de publicación científica en Estados Unidos la Review of Social Economy, Forum for Social Economics y International Journal of Social Economics; los cuales presentan estudios empíricos y teóricos sobre la economía social. En estos, se identifican múltiples autores contemporáneos con diversos aportes en el campo de Social Economy como Elliott, J.E., McMaster, R., Dugger, W.M., O'Boyle, E.J, Figart, D.M., Hodgson, G.M., Solterer, J., Jensen, H.E., Mcmurtry JJ., Bretos I. y Cote D., entre otros.

\subsubsection{Alemania: Economía Social de Mercado}

En Alemania, se ha presentado una trayectoria de economía social de mercado, naciente entre raíces religiosas e integración a través de sociedades mutualistas y cooperativas, donde la cohesión principalmente de los trabajadores se consolidó a mediados del siglo XIX por las nociones expuestas por líderes como Ludwig Gall, Friedrich Harkort y Stephan Born (Monzón, 1989; Rubel, 1977). En Alemania, se desarrolló un enfoque denominado como Economía Social de Mercado especialmente después de la posguerra, identificado como un modelo sociopolítico planteado por Ludwig Erhard y consolidado posteriormente por Alfred Müller Armack en su obra Dirección económica y economía de mercado (Wirtschaftslenkung und Marktwirtschaft), escrita en 1946, que contribuyó, en colaboración con otros académicos como Wilhelm 
Röpke, Alexander Rüstow, y los integrantes de la Escuela de Friburgo, Walter Eucken, Leonhard Miksch y Franz Böhm, a la fundamentación de su concepción teórica y posterior perfil dentro del pensamiento del ordoliberalismo. Según su definición la Economía Social de Mercado es la combinación del principio de la libertad de mercado con el principio de la equidad social a partir del concepto de la libertad del hombre complementada por la justicia social. Pretendiendo sintetizar todas las ventajas del sistema económico de mercado como iniciativa individual, productividad, eficiencia, tendencia a la autorregulación, con los aportes fundamentales de la tradición social cristiana de solidaridad y cooperación (Chaves y Demoustier, 2013). Históricamente, y previo a su consolidación posguerra, la economía social de mercado, surge en la articulación de cuatro movimientos que defendían el mercado de la competencia; Asociación para la Política Social (Verein für Sozialpolitik), el ordoliberalismo, la Escuela de Friburgo y el pensamiento social cristiano (Lucia et al., 2009).

Se establecen como inicios de los modelos de economía social en Alemania, el cooperativismo en lugares rurales y urbanos, y las cooperativas de ahorro, crédito y comercialización. Sin embargo, en relación al paralelo del modelo Francés, discrepa conceptualmente y en principios organizacionales del modelo Alemán, teniendo en cuenta que los sistemas institucionales son divergentes desde la conformación de este sector en cada país, de acuerdo al criterio de Hans Münkner, debido a que las directrices jurídicas en Alemania conciben las cooperativas como empresas mercantiles para la autopromoción de sus socios, en tanto que las asociaciones hacen parte de la categoría de organizaciones de interés general en favor de terceros que no son socios. Es así, como las entidades que se categorizan como de utilidad pública lo son por su finalidad. Desde esta perspectiva, sería complejo distinguir empresas sindicales o instituciones públicas que ofrecen servicios de carácter general y que no necesariamente son de carácter privado, entonces no pertenecen dentro del esquema francés de la economía social (Montolio, 2002).

Según la visión de Müller Armack, como uno de sus principales fundadores, el sentido de la economía social de mercado, que es la denominación hegemónica en Alemania, es la articulación del principio de la libertad del mercado con el principio de la equidad social, es decir, libertad del hombre complementada por la justicia social, dentro de un orden de responsabilidad personal y social (Resico, 2009). La economía social de mercado, enfoca su desarrollo en la iniciativa privada de los individuos, en condiciones de competencia equitativas que impidan la concentración de la riqueza, donde el mercado regula la asignación de recursos y formación de precios, y con deberes y responsabilidades de los individuos en su rol social; este conjunto de factores concibe lo denominado por sus autores como la paz social y el bienestar como bien común. Por lo tanto establecen tres principios orientadores para la economía social de mercado, la responsabilidad individual, la solidaridad constructiva y la subsidiariedad (Frisch, 2009). Como investigadores que han contribuido al estudio de la economía social de mercado en los últimos años se identifican algunos como Goldschmidt, N., Joerges, C., Luetge, C., Behrens, M., Pies, I., Scharpf, F.W. Ebner, A., Helfen, M., Mukerji, N., Felice F., Gerbrandy A., Von Prollius M., y Pennings F.

\subsubsection{Reino Unido: Cooperativismo obrero y voluntary sector}

En el Reino Unido e Irlanda, se identifican como organizaciones de carácter filantrópico con impacto comunitario, tanto la economía social (Monzón y Chaves, 2012a) como la Economía Solidaria (Singer, 1997) se presentan históricamente relacionadas a las primeras cooperativas a finales del siglo XVIII principios del XIX; influenciadas por el inglés Robert Owen, William Thompson, George Mudie, William King, Thomas Hodgskin, John Gray y John Francis Bray quienes fortalecieron la integración mediante el cooperativismo y el sindicalismo (Cole, 2018; Monzón, 1989), al consolidar propuestas alternativas de autogestión para mitigar la pobreza de los trabajadores (Chaves y Monzón, 2012).

En 1790, se presentó el auge de las Friendly Societies, en conjunto con una fuerte integración con los sindicatos, orientados a la emancipación de las clases trabajadoras. Además, se establece en Londres en 1895 la Alianza Cooperativa Internacional (ACI), donde se configuran los principios que caracterizan estas organizaciones de economía social; siendo democráticas, con igualdad de sus integrantes sin importar el capital aportado, y con asignación de excedentes a fines colectivos. Más adelante, se configuran como un sector voluntario y de convergencia de intereses comunitarios y laborales que buscan fines principalmente sociales.

\subsubsection{España: Economía Social CIRIEC}

Araya et al. (2019), resaltan el desarrollo del concepto de economía social en diferentes países europeos, que si bien presentan un bagaje histórico que emerge en el siglo XIX, solamente hasta la década de los noventa del siglo XX tiene un visible reconocimiento de la Unión Europea, a través de figuras jurídicas para caracterizar y promover las organizaciones de este perfil (Baturina, 2018; Chaves et al., 2013). En España se establece la Ley de Economía Social en el 2011, definiendo la economía social como el conjunto de actividades económicas y empresariales privadas que desarrollan fines para satisfacer el interés colectivo de 
sus integrantes, con primacía de las personas y del fin social sobre el capital, autónomas, democráticas, con promoción de la solidaridad interna y con la sociedad que favorezca el compromiso con el desarrollo local, la igualdad y con independencia respecto a los poderes públicos (Fajardo, 2012). Armonizando conceptos, en el año 2012 el CIRIEC formuló una definición de economía social articulada al Sistema Europeo de Cuentas Nacionales y Regionales, que caracteriza a dichas entidades como de carácter privado, formalizadas, autónomas y democráticas, de voluntaria adhesión, creadas para responder a las necesidades de sus miembros a través del mercado, y reinvirtiendo sus excedentes en su fin social (Monzón y Chaves, 2012b).

De acuerdo a la definición de economía social que presenta Fajardo (2018), en la cual, realiza una identificación desde la perspectiva jurídica de las empresas que la conforman en España, y expone un debate sobre el concepto emitido por la Ley de Economía Social de 2011; estableciendo que las entidades de economía social son personas jurídicas de derecho privado, que desarrollan una actividad económica con propósitos de interés general, de forma directa o en conjunción con los intereses de sus miembros usuarios, dando prioridad a las personas y del objeto social sobre el capital. Los beneficiarios de esta actividad se podrían categorizar en tres grupos; un primer grupo de colectivos genéricos como usuarios, consumidores, profesionales, proveedores, trabajadores, desempleados, discapacitados, etc. Un segundo grupo donde son los mismos propietarios como en las figuras de cooperativas, mutualidades, sociedades laborales, sociedades agrarias de transformación, etc. Un tercer grupo que excluye a los dos anteriores a través de figuras como asociaciones, fundaciones, empresas de inserción, centros especiales de empleo, etc., (Fajardo, 2018). Tanto la Ley de Economía Social en España, como la Ley no 2014-856 de Economía social y solidaria en Francia, presentan un doble criterio, para determinar la naturaleza de las entidades que pertenecen al tercer sector; un criterio que delimita a partir de la figura jurídica y otro criterio definido por sus principios y funcionamiento como organización. Estos conceptos, son precedentes que han consolidado el enfoque de la Social Economy Europe (Battisti et al., 2020), que tiene por objetivo promover el desarrollo y reconocimiento de la economía social en el continente europeo (Fajardo y Maestre, 2009), estableciendo la carta de principios de la economía social donde además de lo anterior, se adiciona propósitos en pro del desarrollo sostenible, la adhesión voluntaria y abierta y la defensa y aplicación de los principios de solidaridad y de responsabilidad. (Chaves y Monzón, 2018)

\subsubsection{Latinoamérica: Economía Social como alternativa}

En cuanto a los países latinoamericanos, según Battisti et al. (2020) y Boulianne (2003), la economía solidaria surge como alternativa al sistema capitalista y a la ineficiencia del sector público, con una fundamentación política para defender los intereses de las poblaciones en situación de pobreza, democratizar los recursos, la justicia social y favorecer la vida digna. En aproximaciones a esta línea de pensamiento, se identifica el aporte de diversos y sobresalientes autores, como Luis Razeto de Chile, Paul Singer de Brasil, José Coraggio de Argentina y Pablo Guerra de Uruguay.

En Latinoamérica, la economía solidaria, se encuentra más relacionada con la economía popular (Chaves et al., 2013), debido a que se concibe como una corriente de transformación social alternativa, que le hace frente al modelo neoliberal económico, especialmente para mitigar la pobreza, el subdesarrollo de los países latinos y la justifica social (Singer, 1997). En divergencia, a los planteamientos europeos, que conciben a la economía solidaria perfectamente compatible con el estado y el mercado, la locución latinoamericana propone un proyecto global alternativo al capitalismo, identificándose como una fuerza de cambio social que le hace frente al movimiento neoliberal.

En este apartado del documento, se realiza un abordaje de los orígenes y referentes teóricos de la economía social y la economía solidaria principalmente de países como Francia, Estados Unidos, Alemania, Reino Unido, España y el bloque latinoamericano, a la luz de los aportes de los principales autores y enfoques que se han consolidado entre el siglo XIX y XX. Denotando las diversas locuciones respecto al contexto de aplicación, principios, concepto y marco jurídico; destacando posiciones convergentes y divergentes entre países y autores dentro de un contexto de construcción y debate actual, lo cual aduce un campo aún en formación, que ha ingresado recientemente con auge en el radar de la comunidad científica internacional, especialmente en nuevas publicaciones indexadas en bases de datos como WoS y Scopus, o en algunos special issue por su creciente relevancia de estudio.

\section{Desarrollo del análisis bibliométrico}

A continuación, se realiza un análisis bibliométrico de la producción científica registrada en WoS y Scopus entre los años 2000 y 2020. 
Figura. 2. Producción científica.

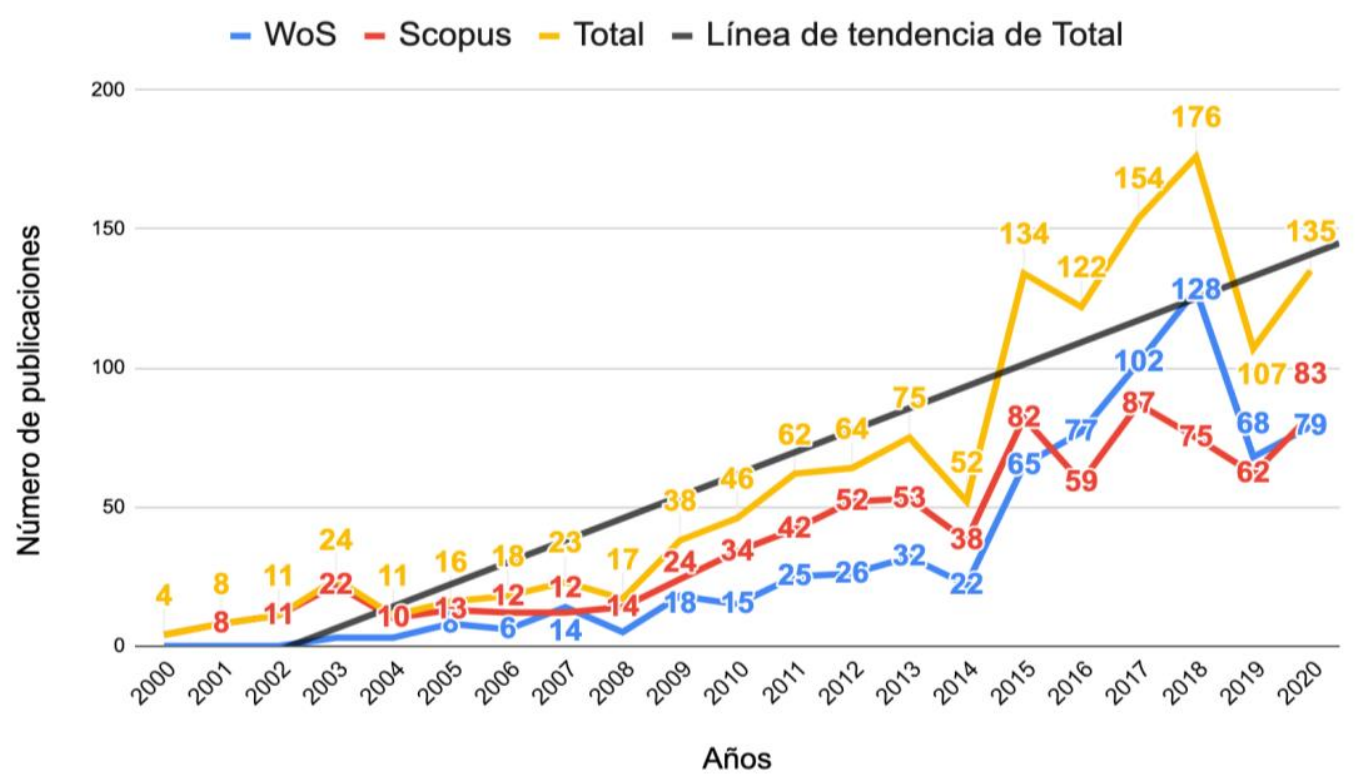

Fuente: Elaboración propia (2021)

La figura 2 representa el número de publicaciones registradas en WoS y Scopus durante el periodo de tiempo comprendido entre el año 2000 y el 2020. En total se identificaron 1297 trabajos relacionados con el tema de economía social y economía solidaria. Se puede visualizar una tendencia de crecimiento en el número de registros, presentando una tasa de crecimiento anual del 15\%, también, se evidencia que más de la mitad de las publicaciones se realizaron en los últimos 5 años. Estos datos reflejan el aumento del interés de la comunidad científica y académica en el tema durante la última década.

En la tabla 2, se presentan los 20 países que aportan el mayor número de publicaciones sobre economía social y economía solidaria en las bases de datos incorporadas en este estudio. Se identifica a España como el país que lidera la lista, con el 17,5\% del número total de publicaciones, seguido por Canadá con el 11,6\% y Estados Unidos 7,7\%. En términos generales, de los 20 países con mayores publicaciones, 10 son europeos y contribuyen con el 47,7\% del campo de estudio, de allí la coherencia con lo abordado en el apartado teórico, sobre la importancia de este continente en los orígenes y fundamentos de la economía social y economía solidaria. Norteamérica representado por Canadá y Estados Unidos concentran el 19,3\% y Latinoamérica como bloque también se destaca con la participación de 6 países, que representan el 16,9\% de las publicaciones. Se resaltada además que los estudios con mayor aporte en este campo de estudio se realizan en inglés, español y francés de acuerdo a los países de ubicación de la comunidad científica

Tabla. 2. Producción por Países.

\begin{tabular}{|c|c|c|c|c|}
\hline \multirow{2}{*}{ País/Región } & \multicolumn{4}{|c|}{ Número de publicaciones } \\
\cline { 2 - 5 } & WoS & Scopus & Total & \% del Total \\
\hline España & 114 & 146 & 227 & $17,5 \%$ \\
\hline Canadá & 64 & 109 & 150 & $11,6 \%$ \\
\hline Estados Unidos & 48 & 72 & 100 & $7,7 \%$ \\
\hline Brasil & 59 & 67 & 114 & $8,8 \%$ \\
\hline Francia & 35 & 76 & 101 & $7,8 \%$ \\
\hline Reino Unido & 42 & 51 & 72 & $5,6 \%$ \\
\hline Rumanía & 39 & 28 & 51 & $3,9 \%$ \\
\hline China & 27 & 33 & 44 & $3,4 \%$ \\
\hline Bélgica & 22 & 25 & 40 & $3,1 \%$ \\
\hline Portugal & 19 & 23 & 34 & $2,6 \%$ \\
\hline Alemania & 27 & 8 & 33 & $2,5 \%$ \\
\hline México & 21 & 9 & 29 & $2,2 \%$ \\
\hline
\end{tabular}




\begin{tabular}{|c|c|c|c|c|}
\hline Italia & 14 & 17 & 25 & $1,9 \%$ \\
\hline Ecuador & 18 & 8 & 24 & $1,9 \%$ \\
\hline Argentina & 18 & 6 & 22 & $1,7 \%$ \\
\hline Polonia & 20 & 5 & 20 & $1,5 \%$ \\
\hline Grecia & 11 & 12 & 17 & $1,3 \%$ \\
\hline Colombia & 15 & 14 & 15 & $1,2 \%$ \\
\hline Chile & 9 & 7 & 14 & $1,1 \%$ \\
\hline Australia & 12 & 10 & 13 & $1,0 \%$ \\
\hline
\end{tabular}

Fuente: Elaboración propia (2021)

En la tabla 3 se clasifican los 20 con mayor número de publicaciones en el tema de economía social y economía solidaria, también se asocia el número de citaciones y el Index h (Este es un indicador utilizado para medir la productividad científica de cada investigador (Hirsch, 2005), de cada uno, de esta forma se encuentra en el primer lugar a Marie J. Bouchard de la Université du Québec à Montréal (Canadá), sin embargo, el autor con mayor número de citaciones es Benoît Lévesque quien a su vez es el autor con el Index h más alto.

Tabla. 3. Producción por Autores.

\begin{tabular}{|c|c|c|c|c|c|c|c|}
\hline \multirow[b]{2}{*}{ Autor } & \multicolumn{3}{|c|}{ WoS } & \multicolumn{3}{|c|}{ Scopus } & \multirow[b]{2}{*}{$\begin{array}{c}\text { Total } \\
\text { publicacion } \\
\text { es }\end{array}$} \\
\hline & $\begin{array}{c}\text { \# de } \\
\text { publicacion } \\
\text { es }\end{array}$ & $\begin{array}{c}\text { \# de } \\
\text { citaciones }\end{array}$ & $\begin{array}{c}\text { Índic } \\
\text { e H }\end{array}$ & $\begin{array}{c}\text { \# de } \\
\text { publicacion } \\
\text { es }\end{array}$ & $\begin{array}{c}\# \text { de } \\
\text { citaciones }\end{array}$ & $\begin{array}{c}\text { Índic } \\
\text { e H }\end{array}$ & \\
\hline Bouchard, Marie J. & 9 & 79 & 5 & 14 & 110 & 7 & 16 \\
\hline $\begin{array}{l}\text { Gaiger, Luiz Inácio } \\
\text { Germany }\end{array}$ & 4 & 20 & 2 & 11 & 58 & 4 & 11 \\
\hline Romero, Nadia & 11 & 25 & 2 & - & - & - & 11 \\
\hline Rousselière, Damien & 6 & 62 & 5 & 9 & 100 & 6 & 10 \\
\hline Chaves, Rafael & 3 & 255 & 9 & 9 & 369 & 10 & 10 \\
\hline Calvo, Sara & 10 & 61 & 4 & 2 & 33 & 3 & 10 \\
\hline Morales, Andres & 10 & 6 & 2 & 2 & 21 & 3 & 10 \\
\hline Lévesque, Benoît & 4 & 1.378 & 22 & 7 & 1.809 & 25 & 9 \\
\hline Laville, Jean Louis & - & - & - & 7 & 475 & 9 & 7 \\
\hline Cace, Sorin & 7 & 100 & 7 & 4 & 87 & 6 & 7 \\
\hline Mook, Laurie & - & - & - & 7 & 495 & 13 & 7 \\
\hline Quarter, Jack J. & - & - & - & 7 & 518 & 14 & 7 \\
\hline Cojocaru, Stefan & 7 & 283 & 13 & 3 & 241 & 27 & 7 \\
\hline Zikidis, Yanni & 7 & 4 & 1 & - & - & - & 7 \\
\hline Hossein, Caroline Shenaz & 4 & 17 & 2 & 5 & 54 & 16 & 6 \\
\hline Fecher, Fabienne & 2 & 70 & 4 & 5 & 180 & 5 & 5 \\
\hline Graefe, Peter & 2 & 74 & 6 & 4 & 113 & 6 & 5 \\
\hline Vaillancourt, Yves & 2 & 47 & 2 & 4 & 60 & 3 & 5 \\
\hline Baptista, Ana Alice & 1 & 144 & 6 & 4 & 144 & 6 & 4 \\
\hline Martinez Arca, Jorge & 4 & 93 & 3 & - & - & - & 4 \\
\hline
\end{tabular}

Fuente: Elaboración propia (2021)

La tabla 4, relaciona las 20 revistas con mayor cantidad de documentos publicados sobre el tema economía social y economía solidaria. Allí se relacionan los registros en cada base de datos y en total. La revista que más publicaciones aporta al área es REVESCO Revista de Estudios Cooperativos de origen 
español con 71 registros, seguida de la también española CIRIEC España Revista De Economía Pública Social y Cooperativa con 63. Estas dos revistas pueden ser consideradas las más importantes en lo que respecta a las publicaciones sobre el tema, debido a que aportan conjuntamente cerca del $10 \%$ de la producción académica en el área.

Tabla. 4. Producción.

\begin{tabular}{|c|c|c|c|c|}
\hline \multirow{2}{*}{ Fuentes } & \multicolumn{3}{|c|}{ Número de publicaciones } & \multirow{2}{*}{$\%$ del total } \\
\hline & WoS & Scopus & Total & \\
\hline Revesco Revista De Estudios Cooperativos & 25 & 47 & 71 & $5,47 \%$ \\
\hline $\begin{array}{c}\text { Ciriec España Revista De Economía Pública Social Y } \\
\text { Cooperativa }\end{array}$ & 32 & 34 & 63 & $4,86 \%$ \\
\hline Annals Of Public And Cooperative Economics & 14 & 36 & 39 & $3,01 \%$ \\
\hline Voluntas & 17 & 13 & 20 & $1,54 \%$ \\
\hline $\begin{array}{c}\text { Digital change in the social economy basics strategies } \\
\text { practice }\end{array}$ & 19 & - & 19 & $1,46 \%$ \\
\hline $\begin{array}{c}\text { Digitaler wandel in der sozialwirtschaft grundlagen } \\
\text { strategien praxis }\end{array}$ & 19 & - & 19 & $1,46 \%$ \\
\hline Sustainability & 14 & 14 & 17 & $1,31 \%$ \\
\hline Review Of Social Economy & 6 & 14 & 16 & $1,23 \%$ \\
\hline International Journal Of Social Economics & 6 & 14 & 14 & $1,08 \%$ \\
\hline $\begin{array}{l}\text { Economie sociale et économie publique social } \\
\text { economy and public economy }\end{array}$ & 11 & - & 14 & $1,08 \%$ \\
\hline $\begin{array}{c}\text { Weight of the social economy an international } \\
\text { perspective }\end{array}$ & 11 & - & 11 & $0,85 \%$ \\
\hline Revue Du Mauss & 0 & 11 & 11 & $0,85 \%$ \\
\hline Calitatea Vietii & 0 & 10 & 10 & $0,77 \%$ \\
\hline $\begin{array}{c}\text { Economía social en contextos de violencia México y } \\
\text { Colombia }\end{array}$ & 10 & - & 10 & $0,77 \%$ \\
\hline Perspectives from social economics & 10 & - & 10 & $0,77 \%$ \\
\hline $\begin{array}{l}\text { Black social economy in the americas exploring } \\
\text { diverse community based markets }\end{array}$ & 9 & - & 9 & $0,69 \%$ \\
\hline Innovations & 0 & 9 & 9 & $0,69 \%$ \\
\hline $\begin{array}{l}\text { Routledge studies in international business and the } \\
\text { world economy }\end{array}$ & 8 & - & 8 & $0,62 \%$ \\
\hline $\begin{array}{l}\text { Social and solidarity economy the world`s economy } \\
\text { with a social face }\end{array}$ & 8 & - & 8 & $0,62 \%$ \\
\hline Espacios & 0 & 8 & 8 & $0,62 \%$ \\
\hline
\end{tabular}

Fuente: Elaboración propia (2021)

La figura 3, ilustra los cuatro elementos principales que componen el análisis bibliográfico, en el primer recuadro se encuentra la red de cocitación de autores, la cual permite identificar los autores más destacados en cuanto recuento de citaciones (White, 2003), para este caso Jacques Defourny, Jean Louis Laville, Rafael Chaves Avila y Carlo Gorzaga, son los más referenciados. En el segundo recuadro se encuentra la red de colaboración de autores y se evidencia el trabajo en conjunto, de los autores que ya se habían mencionado anteriormente, como es el caso Marie J. Bouchard, Damien Rousselière y su estrecho vínculo literario. La red de colaboración entre países reitera el protagonismo de España.

Por último se encuentra la red de coocurrencia de palabras, en donde se evidencian dos grandes grupos de palabras compuestas; el primero (en rojo) por palabras como economía social, economía, y el segundo (en azul) ilustrando variables como condiciones socioeconómicas, desarrollo social. Dos palabras se muestran como pertenecientes a ambos grupos, desarrollo sustentable y desarrollo económico. 
Figura. 3. Redes.

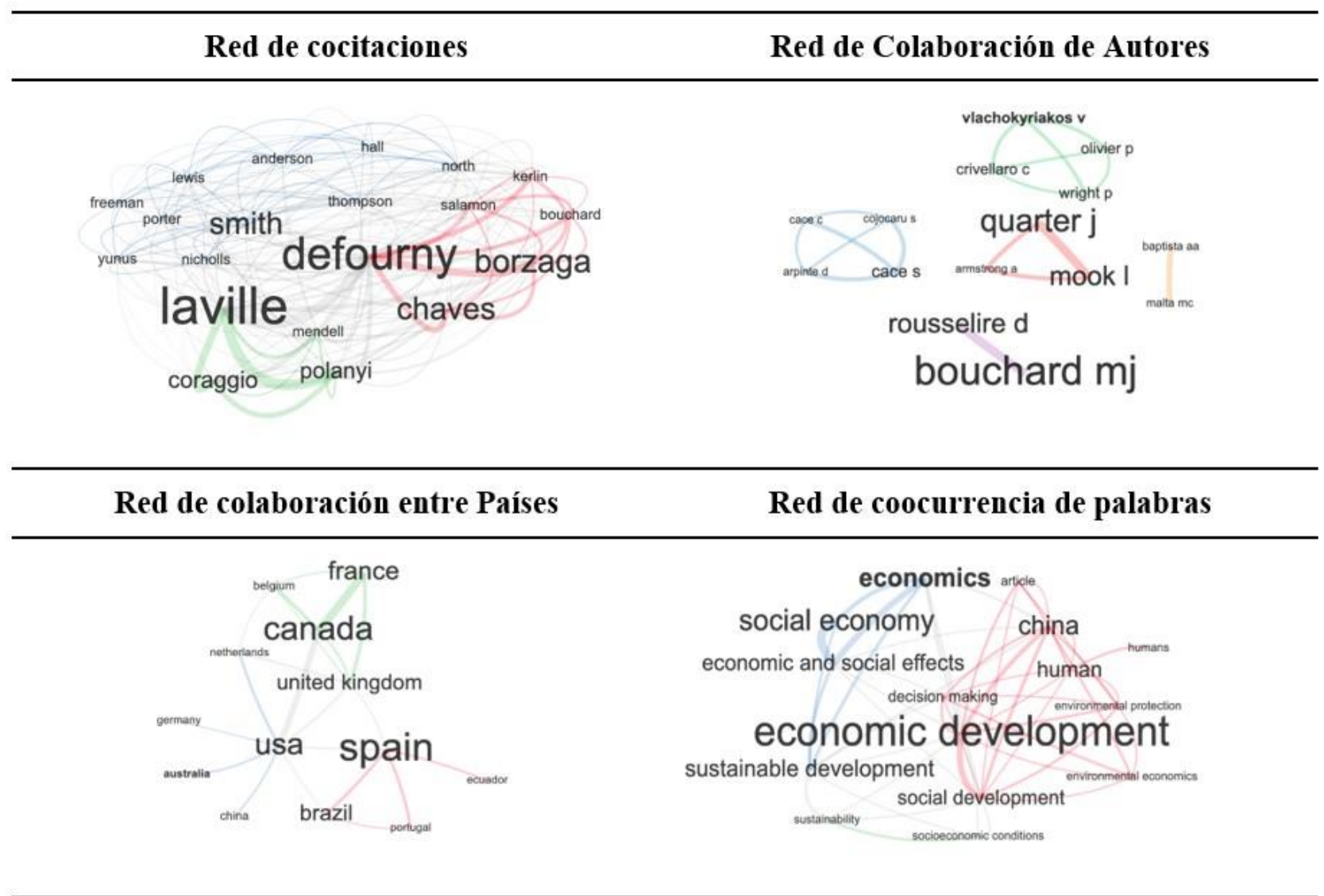

Fuente: Elaboración propia (2021)

\subsection{Análisis de red}

A través de este análisis, se lograron determinar los documentos más relevantes en el área. Se seleccionan para su revisión, los documentos con los indicadores más altos, y se organizan empleando la metáfora del árbol de la ciencia. Diez clásicos (raíces), diez estructurales (tronco) y cuarenta recientes (hojas). Para establecer las subáreas o áreas comunes de investigación, se utilizó el algoritmo de clusterización propuesto por Blondel et al. (2008), de esta forma se identifican cuatro principales grupos, los cuales pueden verse representados en las hojas. Figura 4. 
Figura. 4. Árbol de la economía social y economía solidaria.

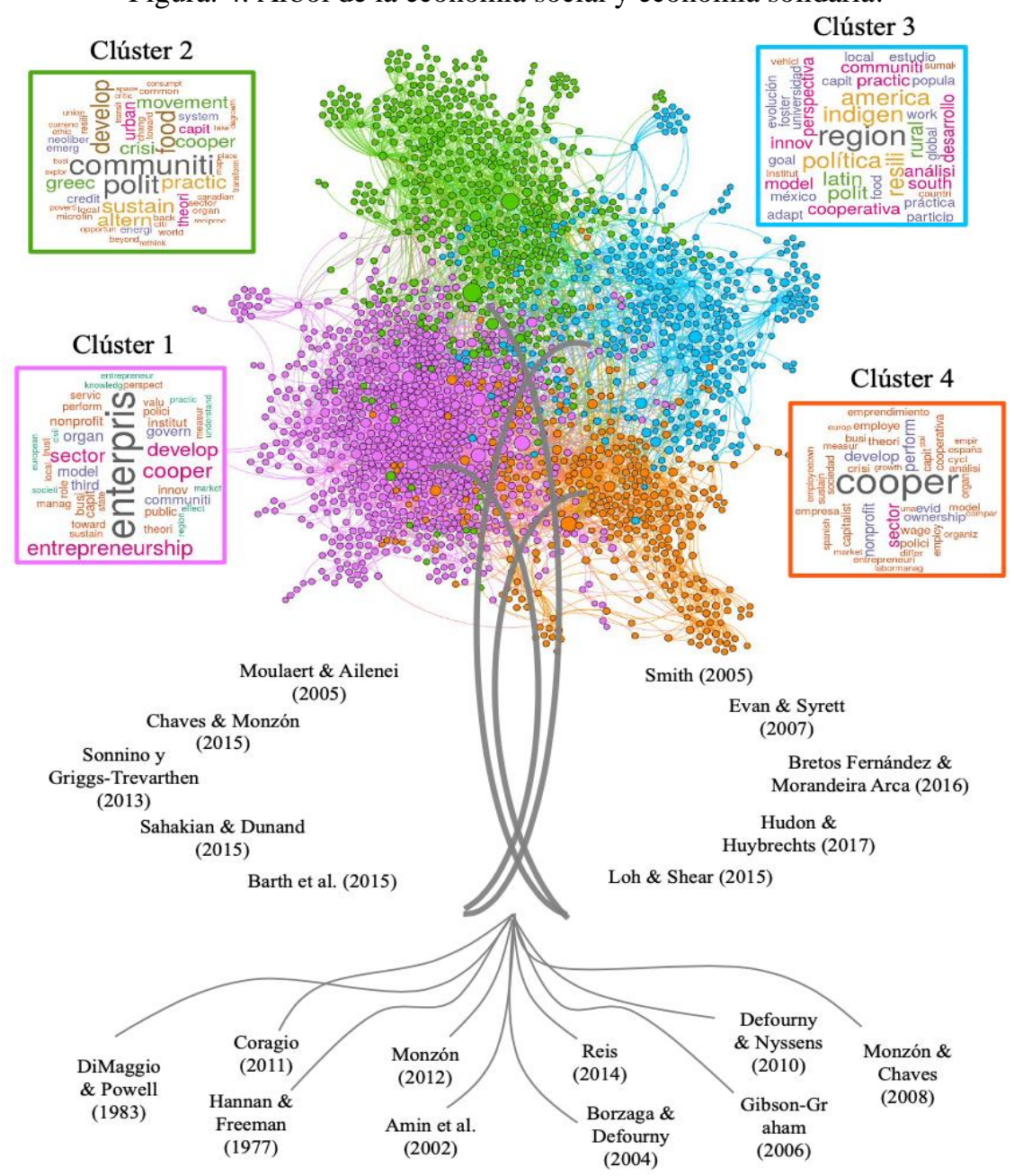

Fuente: Elaboración propia (2021)

Para identificar de forma preliminar las temáticas de cada subárea (clúster), se emplea minería de texto, específicamente, se emplea el paquete WordCloud (Ohri, 2012), el cual, genera nubes de palabras a partir de los títulos y palabras clave de todos los documentos que integran cada clúster. Así mismo, se eligen los diez documentos con mejor PageRank (Page et al., 1999), siendo este indicador un parámetro que permite establecer desde una mirada cuantitativa, los documentos más relevantes dentro de un grupo, esto basado en sus citaciones (Ding et al., 2009; Yan et al., 2010).

A continuación se realiza el análisis de los documentos que integran el árbol de la economía social y economía solidaria.

\subsubsection{Raíz (Clásicos)}

Los documentos que componen la raíz de esta revisión de literatura, están categorizados como aquellos cuyo indegree es el más alto, es decir, agrupa artículos de alta citación, mostrando su carácter clásico y hegemónico. En este apartado se analizan 10 registros considerados como predominantes según lo indicado anteriormente.

A finales del siglo XX, autores como DiMaggio y Powell (1983), resaltaron la necesidad del desarrollo de teorías que aporten a la comprensión de los impactos desfavorables del isomorfismo organizacional, concepto explicado por Hannan y Freeman (1977), en el que hacen apología del concepto de la ecología en las organizaciones, por su factor de selección natural, esto caracterizado por el canibalismo competitivo propio del capitalismo. Por su parte Amin et al. (2002), dimensionan la economía social como una "tercera vía", en la cual, no existe un modelo empresarial estándar que se pueda aplicar uniformemente a todas las organizaciones, por lo que la economía social se convierte en una alternativa viable para solucionar cuestiones sociales y estructurales en comunidades afectadas por los modelos empresariales existentes, dando cabida a un nuevo paradigma organizacional a partir de la economía social (Reis, 2014).

En cuanto a su desarrollo conceptual de mayor fuerza y rigor teórico en Europa y Estados Unidos, autores como Gibson-Graham (2006), quien plantea modelos de economías alternativas frente a los ordenamientos 
capitalistas de favorable recepción en estos tiempos de apertura pluralista. De igual forma Monzón y Chaves (2008), hacen alusión al crecimiento dinámico de la economía social en Europa y establecen nociones conceptuales para el reconocimiento de la economía social y su relevancia como tercer sector económico de este continente, siendo reforzados sus aportes mediante la ampliación de la caracterización de las organizaciones sociales. En un estudio posterior sobre el modelo de desarrollo social, se aborda este tipo de organizaciones en los 27 estados que componen la UE, estudiando la evolución y tamaño, entre otras contribuciones esenciales para categorizar su desempeño (Monzón, 2012).

En un paralelo de avances y limitaciones entre Europa y Estados Unidos de la economía social, Kerlin (2006), hace evidente la observación del crecimiento de este tipo de organizaciones desde 1980, haciendo notar sobre la exigua de estos modelos organizacionales alternativos, haciendo además explícita la manera que se omitió una oportunidad para originar una estructura investigativa de mejor contribución a esta línea de la economía. Así mismo, Defourny y Nyssens (2010) refuerzan el paralelo euro-americano de este concepto entre coincidencias y divergencias y su evolución histórica. Identificando como una divergencia emergente en los últimos años, la necesaria diferenciación de la economía social con las empresas sociales, desde la perspectiva de Borzaga y Defourny (2004), que presentan un marco para una teoría organizacional social soportados en las experiencias de los emprendimientos sociales, pero dejan entrever las restricciones de este tipo de organizaciones que pueden ser vulnerables en ciertos contextos competitivos.

Para el entorno latinoamericano, Coraggio (2011), invita a debatir propuestas sobre el sentido de la economía social y economía solidaria, de las formas para lograrla en un contexto que supere el formato del capitalismo, pudiendo brindar nuevas posibilidades a sus pueblos. Como complemento de lo anterior, Scott (2015), presenta propuestas que además de refrendar la dimensión histórica y teórica del capitalismo social, soportado en ejemplos visibles en diferentes escenarios del mundo, reitera su carácter redistributivo del modelo, las particularidades institucionales para su fortalecimiento y la transferencia a otras esferas socioeconómicas.

\subsubsection{Tronco (Estructurales)}

En esta categoría, se abordan las publicaciones sobre la temática de estudio, que comprenden las investigaciones que conectan lo expuesto por los autores y documentos de fundamentación clásica, con los autores y planteamientos sobre economía social y economía solidaria más recientes; siendo una categoría que expone los modelos y orientaciones que consolidan el estudio científico y técnico en este campo.

Moulaert y Ailenei (2005), proponen una perspectiva para la definición de la economía social, a partir de la revisión de la literatura académica tanto actual como histórica. Complementan este esbozo los autores Sahakian y Dunand (2015), que comparan experiencias de la economía social y economía solidaria en cuanto a la conceptualización y la práctica en diferentes contextos. También se identifican publicaciones científicas que indagan los impactos de la economía social a nivel regional y local, en diferentes líneas de tiempo y lugares. Smith (2005), aborda el impacto de las organizaciones de la economía social en el desarrollo de la ciudadanía social. Por otro lado, en cuanto a empresas sociales, Sonino y Griggs-Trevarthen (2013), analizan casos de estudio en el Reino Unido, su potencial de expansión y su capacidad de resiliencia y adaptación a los cambios de las comunidades locales. Se encuentra también el análisis y estudio de diez organizaciones de la economía social en Australia en cuanto a sus lógicas institucionales y los ambientes propicios para su desarrollo (Barth et al., 2015).

Como se ha establecido anteriormente, las principales investigaciones se han desarrollado en Europa y Estados Unidos, por lo que los aportes más significativos son de estas regiones. Loh y Shear (2015) abordan un análisis crítico a la ideología capitalista, exponiendo una perspectiva de economía solidaria como una serie de teorías y prácticas con capacidad transformadora y democrática a través de estudios de caso de proyectos de economía solidaria en tres ciudades de Massachusetts en Norteamérica. Le siguen otros autores que estudian la evolución socio-económica de las organizaciones de la economía social en el País Vasco durante periodos de crisis económica (Bretos y Morandeira, 2016). En cuanto a Estados Unidos, se realiza un estudio que examina el potencial de transformación de la economía solidaria desde una perspectiva de movimiento social local y como una alternativa a las limitaciones del capitalismo (Chaves y Monzón, 2012), mediante el estudio de caso de la economía solidaria en un sector de comidas urbanas en Boston (Loh y Shear, 2015).

También se abordan dos investigaciones, de relevancia en este campo por Evan y Syrett (2007), orientadas a fortalecer la concepción teórica en el estudio del capital social y la obtención de recursos en la economía social, resaltando que su planteamiento ha sido el eje de estudios académicos y de política pública. Además, se expone la importancia de posicionar a la economía social como el tercer gran sector institucional de la economía a partir de sus modelos microeconómicos, estudiando de manera pluralista, siendo comparada con el sector de instituciones sin ánimo de lucro (Chaves y Monzón, 2012). Se identifican también, los planteamientos en cuanto a la contribución y sinergia conceptual entre la economía social y el desarrollo sostenible, dado el posible aporte de estas organizaciones según sus principios de impacto social 
(Hudon y Huybrechts, 2017)

\subsubsection{Hojas (perspectivas)}

Con el proceso de revisión bibliométrica realizado, se establecieron 4 subáreas (clústers) principales, emergentes sobre este campo de estudio, las cuales denotan las líneas de investigación más recientes. A continuación se presenta cada una de ellas.

\section{Clúster 1: Emprendimiento Social}

Aunque algunos autores no están de acuerdo en articular o confundir la economía social con este cluster, en la literatura se identifica como una línea emergente algunos estudios de autores que están a favor de relacionar la economía social con modelos de emprendimiento social, como mecanismo para generar valor, lo que constituye en una marcada tendencia en los últimos años, que concibe una ruptura de la propensión del espíritu empresarial convencional que persigue alcanzar un valor económico tangible (Mair y Martí, 2006), sustentado en el reconocimiento de oportunidades en la satisfacción de necesidades sociales a pesar de su carácter privado (Defourny y Nyssens, 2008; Lee, 2020), bien sea por la iniciativa de uno solo miembro o de un grupo de gestores en el reconocimiento de ese valor, admitiendo que estos emprendedores sociales se perfilan en muchos casos como inversores socio-laborales (Navarro et al., 2011), en donde la innovación social juega un papel trascendental para el éxito de este modelo organizacional, siendo común la escasez de recursos disponibles en este empeño emprendedor (Peredo y McLean, 2006). Es pertinente destacar que existen enfoques donde no contemplan el emprendimiento social como parte intrínseca de la economía social, debido a los principios que la rigen, y que fueron planteados en la sección de origen y referente teórico, aclarando además que en los términos de consulta en las bases de datos no se contempló expresiones como emprendimiento social, empresas sociales o innovación social.

Las limitados puntos para estimular el emprendimiento en las economías de mercado de corte capitalista, permiten que muchos busquen alternativas en los emprendimiento sociales, no solo como socios, sino como trabajadores que originan impactos positivos en las condiciones socioeconómicos en rangos de la población, en especial aquellas con indicadores de alta vulnerabilidad (Kontogeorgos y Chatzitheodoridis, 2019), es por esto que instituciones como la OCDE, alienta en la promoción de la cultura emprendedora en la educación de los jóvenes, convirtiéndolo en un eje central en la educación europea, siendo alineado con el fomento de la economía social, vista como una apuesta estratégica para el desarrollo económico y social de la zona, tal es el caso de la "Declaración de Madrid" de 2017 (Espada et al., 2018), que institucionaliza el emprendimiento, articulado con modelos soportados en la economía social para ser difundido en diferentes niveles de la formación educativa, indicando que existen espacios disruptivos y emergentes para seguir promocionando la economía social, como un tercer sector, el cual alberga un carácter sostenible en su enfoque, es decir, la creación de valor sostenible (Defourny y Nyssens, 2021; Espada et al., 2018; Salamon y Wojciech Sokolowski, 2016).

\section{Clúster 2: EI Desarrollo de Comunidades y la Sostenibilidad}

En esta perspectiva se identifica como una de las principales problemáticas globales, el precario tejido social en muchos países que se desencadena en otras alteraciones sociales más graves, por lo que la economía social con su enfoque holístico, se ha convertido en un modelo eficaz para crear condiciones incluyentes aparte de una cohesión social sostenible (Predețeanu et al., 2019), dirigida a comunidades vulnerables, teniendo en cuenta que sus principios de equidad, inclusión, cooperación, solidaridad y democracia, convergen con varios elementos constituidos en los Objetivos del Desarrollo Sostenible -ODS- (Chaves y Gallego, 2020). En este sentido es conveniente considerar lo propuesto por Fournier (2008), y en línea con los preceptos de las corrientes "duras" del desarrollo sostenible, surgidas en Francia en el último decenio, en la conveniencia de lograr decrecimientos económicos en contraposición de los intentos institucionales de mantener sostenible lo que al ritmo del capitalismo del consumo es incapaz (Navarro et al., 2011; Schneider et al., 2010).

Del mismo modo, la necesidad de revertir las relaciones de mercado por las relaciones humanas en función de la satisfacción de las necesidades fundamentales (físicas y sociales), a través un nuevo paradigma: el medio ambiente, y este como un nuevo modelo económico (Kontogeorgos y Chatzitheodoridis, 2019; Monna, 2017). Esta locución implica la generación, diseño e implementación de un nuevo orden de políticas públicas, cuyo enfoque innovador amplíe las posibilidades del verdadero impacto de la economía social en las comunidades que aún aquejan restricciones para el acceso a recursos financieros (Chaves y Gallego, 2020). 


\section{Clúster 3: La Economía Social en Países Emergentes. Latinoamérica}

Como otra perspectiva emergente, se estudia las dificultades propias de los países en desarrollo y la aplicación de herramientas para mejorar su desempeño socioeconómico, es un reto fundamental para mejorar las condiciones de vida de sus ciudadanos, por lo que la economía social se ratifica como una alternativa social y económicamente viable para solucionar diversos problemas relacionados con la sostenibilidad, siendo aplicado de manera efectiva en varios países de economías desarrolladas, emulándose con casos de éxito en naciones en vías de desarrollo particularmente para Latinoamérica, cuyas apuestas de desarrollo se sustentan en actividades extractivas (Saguier y Brent, 2017), algunas de estas naciones han implementado políticas públicas para hacer de este tercer sector, un mecanismo de superación de los obstáculos propios de los modelos persistentes que no incluyen elementos valiosos de la economía social, tales como como la cooperación, el beneficio mutuo y la democracia (Ferguson, 2018). Estudios focalizados realizados en Bolivia y Chile, demuestran los atributos de la economía social a la generación de empleo y su aporte positivo al PIB, a pesar de la existencia de una alta proporción de organizaciones sociales similares que operan bajo la informalidad, por lo que los indicadores podrían ser más generosos (Araya et al., 2019; Cid et al., 2019; Ferguson, 2018).

En Países como Ecuador y Brasil, los estudios ratifican las tendencias señaladas anteriormente, al comprobarse la estrecha relación entre el fomento de la economía social y economía solidaria, y los desempeños de los ciclos económicos expansivos de su economía, gracias a sus principios comunes de igualdad, solidaridad, de comunidad, de compartir, de la participación ciudadana y la ayuda mutua (Buendía et al., 2020). Estos resultados coinciden con desempeños evidenciados en Uruguay, que además de contribuir al desarrollo económico del país, ha mejorado las relaciones de asignación de factores de producción, distribución de la riqueza y acceso a recursos, favoreciendo las intenciones para emprendimientos en este campo (Azevedo et al., 2019; Buendía et al., 2020; Carvajal y Calvache, 2019; Castiñeira, 2020). Estos resultados contrastan con la realidad cubana, que es el país primigenio de estos modelos de economía social en el continente americano, no obstante, recientemente, los observables cambios de la composición de la organización social de tipo público-estado a lo privado que ha sido lento pero paulatino (Betancourt, 2018).

\section{Clúster 4: Cooperativismo y Economía social y Economía Solidaria.}

En la actualidad, las disrupciones sectoriales y empresariales están al orden del día, de tal manera que los diferentes países deben buscar alternativas sostenibles para ponerse a tono con esas posibilidades, es así como la innovación social es una de ellas, específicamente en el tercer sector que poseen las cooperativas en sus diferentes modalidades de prestación de servicios solidarios inclusivos es innegable, a través de la democratización propietaria y la distribución equitativa de sus utilidades entre los asociados y no con los propietarios capitalistas (Chaves y Savall, 2014; Pavlovskaya et al., 2020), cuya bondad de facilitar acceso de incontables bienes y servicios a los asociados que el sistema tradicional de comercialización y financiamiento no proporciona, que además deben aplicar normas con el mismo rasero de control y fiscalización de las organizaciones de capital privado con objetivos sociales diametralmente opuestos, notándose deficiencia de políticas de estímulo para estas organizaciones sociales en numerosos países del mundo a través de estudios que comprueban su aporte al desarrollo y empleo (Pavlovskaya et al., 2020; Ríos et al., 2014). También se resalta la capacidad resiliente en las crisis económicas de las cooperativas frente a otras formas organizacionales convencionales, coadyuvado por el activismo político y el propio tamaño del sector cooperativo (Monteagudo y Buendía, 2020).

De otra parte, estudios desarrollados en España y Francia evidencian el aporte anticíclico a la economía de un país (Pérotin, 2006; Ríos et al., 2014; Sala et al., 2017), su contribución alternativa al empresariado capitalista en momentos de crisis económicas y niveles de desempleo agobiantes, dada su capacidad de crear capital social y expandirlo a entornos locales comunitarios (Bretos et al., 2018; Buendía y Côté, 2014; Carini y Carpita, 2014); que demuestra la necesidad de ahondar en la diatriba de cooperativas y capital social, además de su influencia del efecto simétrico entre diferentes zonas geográficas en un país.

\section{Conclusiones}

La presente investigación permite contribuir a la comprensión y análisis de la economía social y economía solidaria, concebido como un modelo de desarrollo económico independiente del sector público y del privado tradicional, denominado por múltiples autores como tercer sector. Así mismo, este estudio comprende el mapeo científico y el análisis mediante la metáfora del árbol; ya que es una herramienta innovadora para realizar una revisión sistemática de literatura, mediante la búsqueda en la base de datos WoS y Scopus como fuente de los documentos. En este estudio se combinaron indicadores bibliométricos y la teoría de redes, empleando las herramientas Gephi, bibliometrix y el software R, lo que permitió analizar la 
producción literaria sobre economía social y economía solidaria; así mismo identificar las líneas de investigación emergentes sobre el tema.

En total se identificaron entre el año 2000 y 2020 un total de 1297 publicaciones registradas en WoS y Scopus relacionados con el tema de economía social y economía solidaria, en sus diferentes expresiones en inglés, español y francés, como idiomas predominantes en este campo de estudio por parte de la comunidad académica, con resultados respectivos del 55\%, 22\% y 7\% de acuerdo al idioma de publicación. Se destacan revistas como Review of Social Economy, Forum for Social Economics y International Journal of Social Economics, Annals Of Public And Cooperative Economics en inglés; mientras que en Francés Revue Internationale de l'économie Sociale, Association Française de Science Économique y Revue Française de Socio-Économie; y se resaltan REVESCO Revista de Estudios Cooperativos, visible en Scopus desde el año 2011, y CIRIEC España Revista de Economía Pública Social y Cooperativa., visible en Scopus desde el año 2007, que representan el 10\% de todas las publicaciones sobre este campo de estudio.

Se evidencia un auge paulatino por abordar esta temática con una tasa de crecimiento anual del $15 \%$, y con más de la mitad de las publicaciones realizadas en los últimos 5 años. España se identifica como el país con mayor contribución en cuanto a publicaciones se refiere con el 17,5\%, seguido por Canadá con el 11,6\% y Estados Unidos 7,7\%. Siendo principalmente los orígenes de países francófonos y anglosajones los que determinan las raíces y fundamentos teóricos sobre la economía social y economía solidaria. Diferenciando las locuciones y desarrollo conceptual de la corriente Économie Sociale en Francia, Social Economy en Estados Unidos, Economía Social de Mercado en Alemania, Cooperativismo obrero y voluntary sector en Reino Unido, Economía social según CIRIEC en España, y Economía Social como modelo alternativo en Latinoamérica, que ha presentado cierta armonía y convergencia por lo menos en el continente europeo en las últimas dos décadas. De los 20 países con mayor aporte en publicaciones, 10 son de Europa, representando el 47,7\%, seguidos por Canadá y Estados Unidos que concentran el 19,3\% y Latinoamérica con la participación de 6 países con el 16,9\% de las publicaciones. En cuanto a autores se destacan Bouchard, Marie J; Gaiger, Luiz Inácio Germany; Romero, Nadia; Rousselière, Damien; Chaves, Rafael; Calvo, Sara; Morales, Andres; Lévesque, Benoît; Laville, Jean Louis; Monzón, Jose Luis, y Cace, Sorin. Además, se mencionan otros importantes autores contemporáneos que aportan a este objeto de estudio en el análisis realizado por cada país y enfoque en el aparto de origen y referente teórico.

Así mismo, se resalta un interés paulatino en la economía social y la economía solidaria de la comunidad científica en países de Europa, Latinoamérica y países como Estados Unidos y Canadá, además de múltiples instituciones de carácter gubernamental. Estableciendo sus orígenes principalmente en Francia durante el siglo XIX, especialmente a partir de la revolución industrial por autores SaintSimon, Fourier, Proudhon y Blanc, en conjunto con los planteamientos de los economistas John Stuart Mill y Leon Walras sobre la integración formal de los trabajadores, a través de figuras cooperativas y mutualistas. Se consolida para finales de la década del setenta, las figuras asociativas, mutuales y cooperativas mediante la CNLAMCA, que posteriormente publicaría en 1980 la Charte de léconomie sociale, donde se expone el concepto de la economía social como entidades independientes del sector público, democráticas, con un régimen especial para destinar sus excedentes para el crecimiento de la misma entidad y orientada a mejorar los servicios para sus asociados y la sociedad. En el mismo sentido en Bélgica, se expone que la economía social comprende principios como: desarrollar servicios para sus socios antes que buscar el lucro, garantizar la democracia, primar la distribución de excedentes en las personas antes que al capital, e independientes del sector público y privado tradicional. Se destaca en el aporte de autores franceses en este campo, al investigador contemporáneo Jean-Louis Laville, fundamentando en Karl Polanyi.

En Estados Unidos, se representa la economía social como el sector no lucrativo (Nonprofit Organizations), denominación establecida por Weisbrod (1986); estableciendo como principales objetivos, su estructura institucional, su carácter privado, autogobernadas, con excedentes reinvertidos en su función principal, y con plena participación voluntaria, según (Salamon y Anheier, 1997). Por lo tanto, las entidades de economía social se denotan de acuerdo a la orientación conceptual y jurídica del país, por ejemplo, en España y Francia, son categorizadas como la economía social y el tercer sector, destacando que el modelo iberico tiene sus adeptos a partir de los estudios del CIRIEC, mientras que Francia se diferencia por lo planteamientos expuestos por la Association d'Économie Sociale. En Alemania se desarrolló un enfoque denominado como Economía Social de Mercado, que tiene como premisa la combinación del principio de la libertad de mercado con el principio de la equidad social mediante la articulación de la libertad y responsabilidad del hombre complementada por la justicia social; en el Reino Unido e Irlanda, se identifican como organizaciones de carácter filantrópico con impacto comunitario, armonizando conceptos; en el año 2012 el CIRIEC formuló una definición de economía social articulada al Sistema Europeo de Cuentas Nacionales y Regionales, estableciendo que son organizaciones de carácter privado, formalizadas, autónomas y democráticas, de voluntaria adhesión, creadas para responder a las necesidades de sus miembros a través del mercado, y reinvirtiendo sus excedentes en su fin social.

En cuanto a países de Asia, se identifica como economía social, sector de cooperación y sistema intermediario; en cuanto a países de áfrica, como sector cooperativo o sector caritativo, mientras que en 
Australia, como sector filantrópico. En el bloque latinoamericano se presentan como economía popular en Ecuador, economía informal en Perú, economía del trabajo en Argentina, Economía Solidaria y Tercer Sector en Brasil y Economía Solidaria en Colombia. Se evoca en este bloque regional un énfasis en la economía solidaria desde la perspectiva como alternativa, al sistema capitalista y a la ineficiencia del sector público, con una fundamentación política para defender los intereses de las poblaciones en situación de pobreza, democratizar los recursos, la justicia social y favorecer la vida digna. Se realizó en este párrafo un colofón a modo de conclusión de las locuciones sobre economía social y economía solidaria en los países representativos en este campo, sin embargo, en el aparto de origen y referente teórico se aborda con más detalle los conceptos y premisas de cada enfoque.

\section{Limitaciones y futuros estudios}

A pesar del rigor y la amplitud del estudio se plantean algunas limitaciones, teniendo en cuenta que el interés es realizar una revisión de literatura y análisis bibliométrico de este campo según las publicaciones y autores, por lo tanto, no se pretende realizar un discurso de tesis, antítesis, síntesis o reflexivo de un enfoque en particular. No obstante que la selección de los documentos se efectuó a partir de un procedimiento objetivo, basado en técnicas cuantitativas y de análisis bibliométrico, teniendo como criterios de consulta las expresiones economía social, economía solidaria, y economía social y solidaria, tanto en inglés, francés y español; en la revisión de la literatura y posterior análisis, se identificaron artículos con ambigüedades en delimitación de conceptos, principios, enfoques y términos, relacionando en ocasiones otros campos de estudio que no tienen relación intrínseca o directa con la economía social o que se conciben como líneas emergentes, lo cual aduce un objeto de estudio en construcción y debate en los últimos años por parte de la comunidad científica. También, el uso principalmente de WoS y Scopus puede resultar como una limitación, ya que, a pesar de ser consideradas las bases de datos más grandes e importantes del mundo, se quedan por fuera algunas revistas y publicaciones que no se encuentran indexadas en sus índices, sin embargo, se contemplaron estudios relevantes de otras fuentes científicas para complementar el análisis de integral de conceptos y aportes en este campo de investigación. Es así, que se hace necesario ampliar este estudio con otras bases de datos, para contrastar los resultados reportados en este estudio.

Se sugiere para futuras investigaciones, tener en cuenta, y explorar tres elementos importantes cuando se desea conceptualizar términos como economía social y economía solidaria. Dichos elementos son: las personas del contexto, la existencia de criterios mínimos teóricos, y las políticas compartidas. De igual forma, su articulación en la construcción de economías sociales y economías solidarias (Pérez, 2015). También explorar las limitaciones de intercooperación, reciprocidad, solidaridad o la superación de las mismas teniendo en cuenta las características actuales del contexto económico (Villalba y Pérez, 2019). A pesar de la evolución que ha tenido el tema en Estados Unidos, Canadá y Europa, queda pendiente un mayor debate sobre la delimitación conceptual y organizacional de la economía social y la economía solidaria (Battisti et al., 2020). Para Núñez et al. (2020), una perspectiva importante a tratar es el aporte de la economía social a la cohesión territorial, particularmente el análisis de su impacto en la zona rural y la convergencia con la sostenibilidad.

A partir de estas perspectivas derivadas de esta revisión, se abren posibilidades investigativas en el campo de la economía social y economía solidaria, que dé cuenta de aspectos como los impactos en los indicadores Gini en países emergentes tras la aplicación de políticas públicas; revisiones transversales que analicen los perfiles psicográficos de las poblaciones beneficiarias, la dinamización de las normas del sector cooperativo y su impacto en el crecimiento de una economía, la diferencias en la condiciones de desarrollo económico y social entre comunidades de una misma región, el ciclo de vida de las empresas nacientes de emprendimientos sociales, así como también el desarrollo de estudios que evalúen el impacto de la economía social y la economía solidaria en la sostenibilidad organizacional, en la educación y sus instituciones en la formación de un sujeto sostenible.

\section{Agenda de investigación}

A continuación se relacionan diferentes temas de investigación que deben ser abordados por investigaciones futuras. 


\begin{tabular}{|c|c|c|}
\hline Perspectiva & Tema & Referencia \\
\hline \multirow[t]{4}{*}{$\begin{array}{l}\text { Emprendimiento } \\
\text { Empresas Sociales }\end{array}$} & $\begin{array}{l}\text { Participación de la mujer, etnias y otras } \\
\text { minorías en los emprendimientos en ESS }\end{array}$ & $\begin{array}{l}\text { (Kontogeorgos } \\
\text { Chatzitheodoridis, 2019) }\end{array}$ \\
\hline & $\begin{array}{l}\text { Resultados del desempeño en empresas } \\
\text { sociales con socio-trabajadores versus } \\
\text { solo socios }\end{array}$ & $\begin{array}{l}\text { (Kontogeorgos } \\
\text { Chatzitheodoridis, 2019) }\end{array}$ \\
\hline & $\begin{array}{l}\text { Evaluación del desarrollo de programas } \\
\text { educativos soportados en la ESS }\end{array}$ & (Espada et al., 2018) \\
\hline & Empresas sociales femeninas & (Defourny y Nyssens, 2021) \\
\hline \multirow[t]{3}{*}{$\begin{array}{ll}\text { El Desarrollo } & \text { de } \\
\text { Comunidades y } & \text { la } \\
\text { Sostenibilidad } & \end{array}$} & $\begin{array}{l}\text { Evolución del indicador Gini y su } \\
\text { relación con la dinámica del tercer sector } \\
\text { en economías emergentes }\end{array}$ & (Predețeanu et al., 2019) \\
\hline & $\begin{array}{l}\text { Avance en el logro de los ODS y la } \\
\text { aplicación de políticas de desarrollo } \\
\text { soportadas en la ESS }\end{array}$ & $\begin{array}{l}\text { (Chaves y Gallego, 2020; Lee, } \\
\text { 2020) }\end{array}$ \\
\hline & $\begin{array}{l}\text { Impacto en la sostenibilidad empresarial } \\
\text { desde la perspectiva de la ESS }\end{array}$ & (Defourny y Nyssens, 2021) \\
\hline \multirow[t]{3}{*}{$\begin{array}{l}\text { La Economía Social en } \\
\text { Países Emergentes: Un } \\
\text { Enfoque Latinoamericano }\end{array}$} & $\begin{array}{l}\text { Estudios transversales de desarrollo } \\
\text { económico y social entre zonas, regiones } \\
\text { o países en la aplicación de políticas } \\
\text { públicas de ESS }\end{array}$ & $\begin{array}{l}\text { (Araya et al., 2019; Ferguson, } \\
\text { 2018) }\end{array}$ \\
\hline & $\begin{array}{l}\text { Análisis cualitativos de la transformación } \\
\text { empresarial basada en modelos de ESS }\end{array}$ & (Betancourt, 2018) \\
\hline & $\begin{array}{l}\text { Evaluación del ciclo económico en } \\
\text { periodos de tiempo entre países } \\
\text { emergentes y desarrollo del sector sector }\end{array}$ & (Buendía et al., 2020) \\
\hline \multirow[t]{3}{*}{ Cooperativismo y ESS } & $\begin{array}{l}\text { Desempeño del sector cooperativo y la } \\
\text { política pública para la ESS }\end{array}$ & (Monteagudo y Buendía, 2020) \\
\hline & Innovación social y desarrollo social & (Pavlovskaya et al., 2020) \\
\hline & $\begin{array}{l}\text { Construcción de capital social y tipología } \\
\text { de ESS }\end{array}$ & (I. Bretos et al., 2018) \\
\hline
\end{tabular}

Fuente: Elaboración propia (2021)

\section{Referencias bibliográficas}

Abad, J. S. (2019) Economía social y solidaria, emprendimiento social y economía popular en la sociedad post-crisis. Revista de Antropología Social, 28(2), pp. 205-226. https://doi.org/10.5209/raso.65612.

Alam, J., Boamah, M. I., y Moir, R. (2018) An examination of the social economy: some new theoretical insights. International Journal of Social Economics, 39, 88. https://doi.org/10.1108/IJSE-10-2016-0274.

Amin, A., Cameron, A., y Hudson, R. (2002) Placing the Social Economy. https://doi.org/10.4324/9780203166123.

Araya, E. L., Vanhulst, J., Aguayo, B. C., y Meyer, R. G. (2019) Panorama de la economía social en Chile: la brecha entre definiciones formales y sustantivas. REVESCO. Revista de Estudios Cooperativos, Tercer Cuatrimestre, $\mathrm{N}^{\mathrm{o}}$ 132, pp. 144-168. https://doi.org/10.5209/reve.65484. 
Arce, V. M. A. (2020) El fomento del cooperativismo a través de la contratación pública sostenible. REVESCO. Revista de Estudios Cooperativos, vol. 133, e67339. https://doi.org/10.5209/reve.67339.

Aria, M., y Cuccurullo, C. (2017) bibliometrix: An R-tool for comprehensive science mapping analysis. Journal of informetrics, 11(4), pp. 959-975. https://doi.org/10.1016/j.joi.2017.08.007.

Aria, M., Misuraca, M., y Spano, M. (2020) Mapping the Evolution of Social Research and Data Science on 30 Years of Social Indicators Research. Social indicators research, 149(3), pp. 803-831. https://doi.org/10.1007/s11205-02002281-3.

Azevedo, F. F. de, de Azevedo, F. F., y Espelt, R. (2019) La evolución e impacto de la economía social y solidaria en Brasil y Cataluña. Confins, 43. https://doi.org/10.4000/confins.24633.

Bar-Ilan, J. (2008) Which h-index? - A comparison of WoS, Scopus and Google Scholar. Scientometrics, 74(2), pp. 257-271. https://doi.org/10.1007/s11192-008-0216-y.

Barth, S., Barraket, J., Luke, B., y McLaughlin, J. (2015) Acquaintance or partner? Social economy organizations, institutional logics and regional development in Australia. Entrepreneurship and Regional Development, 27(3-4), pp. 219-254. https://doi.org/10.1080/08985626.2015.1030458.

Bastian, M., Heymann, S., y Jacomy, M. (2009) Gephi: an open source software for exploring and manipulating networks. International AAAI Conference on Weblogs and Social Media. https://gephi.org/users/publications/.

Battisti, T. L., Marcuello, S. C., y Messias, B. J. (2020) Las perspectivas Latinoamericana y Europea de la Economía Solidaria. REVESCO. Revista de Estudios Cooperativos, vol. 134, e69171. https://doi.org/10.5209/reve.69171.

Baturina, D. (2018) CIRIEC: Recent Evolutions of the Social Economy in the European Union. Revija za socijalnu politiku, 25(2), 107-122. https://doi.org/10.3935/rsp.v25i2.1543.

Betancourt. (2018) Social and Solidarity Economy and the Transformation of the Cuban Economic Model. En International Journal of Cuban Studies, vol. 10, № 2, p. 209. https://doi.org/10.13169/intejcubastud.10.2.0209.

Blondel, V. D., Guillaume, J.-L., Lambiotte, R., y Lefebvre, E. (2008) Fast unfolding of communities in large networks. Journal of Statistical Mechanics: Theory and Experiment, 2008(10), p. 10008. https://doi.org/10.1088/17425468/2008/10/p10008.

Bond, M., Zawacki-Richter, O., y Nichols, M. (2019) Revisiting five decades of educational technology research: A content and authorship analysis of the British Journal of Educational Technology. British journal of educational technology, 50(1), pp. 12-63. https://doi.org/10.1111/bjet.12730.

Borzaga, C., y Defourny, J. (2004) The Emergence of Social Enterprise. Psychology Press. https://emes.net/publications/books/the-emergence-of-social-enterprise/.

Botelho, L. L. R., Wuerges, A. F. E., Schneider, P., Belmonte, D. J., Minetto, C., Macedo, M., y Trindade, E. P. (2015) Revisión integradora de la producción científica nacional de la relación entre tecnología social, economía solidaria e incubadoras tecnosociales de cooperativas populares. http://www.revistaespacios.com/a15v36n07/15360705.html.

Bouchard, M. J. (2009) The Worth of the Social Economy: An International Perspective. Peter Lang. https://www.peterlang.com/view/title/11631.

Boulianne, M., Fraisse, L., y Ortiz, H. (2003) L'espérance économie solidaire a principes économie solidaire et mondialisation. Revue du MAUSS, 21(1), p. 47. https://doi.org/10.3917/rdm.021.0047.

Bretos, F. I., y Morandeira, A. J. (2016) La economía social ante la actual crisis económica en la Comunidad Autónoma del País Vasco. REVESCO. Revista de Estudios Cooperativos, Tercer Cuatrimestre, No 122, pp. 7-33. https://doi.org/10.5209/rev_REVE.2016.v122.52020.

Bretos, I., Díaz, F. M., Marcuello, C., y Marcuello, C. (2018) Cooperativas, capital social y emprendimiento: Una perspectiva teórica. REVESCO. Revista de Estudios Cooperativos, Segundo Cuatrimestre, No 128, pp. 76-98. https://doi.org/10.5209/reve.59775.

Buendía, M. I., Álvarez, H. A., y Menéndez, M. M. (2020) Business Cycle, SSE Policy, and Cooperatives: The Case of Ecuador. En Sustainability, Vol. 12, No 13, p. 5485. https://doi.org/10.3390/su12135485.

Buendía, M. I., y Côté, A. (2014) Desarrollo territorial rural y cooperativas: un análisis desde las políticas públicas. En Cuadernos de Desarrollo Rural, Vol. 11, No 74, p. 20. https://doi.org/10.11144/javeriana.crd11-74.dtrc.

Buitrago, S., Duque, P., y Robledo, S. (2020) Branding Corporativo: una revisión bibliográfica. ECONÓMICAS CUC, 41(1). https://doi.org/10.17981/econcuc.41.1.2020.Org.1.

Carini, C., y Carpita, M. (2014) The impact of the economic crisis on Italian cooperatives in the industrial sector. Journal of Co-operative Organization and Management, 2(1), pp. 14-23. https://doi.org/10.1016/j.jcom.2014.03.001.

Carvajal, O. V. J., y Calvache, V. J. J. (2019) De economía popular a economía popular y solidaria en Quito: el caso de los indígenas urbanos inmigrantes del barrio San Roque. CIRIEC-España, Revista de Economía Pública, Social y Cooperativa, No 96, 155. https://doi.org/10.7203/ciriec-e.96.12148.

Castelao, M. E. (2016) Las políticas públicas y su visión de la economía social y solidaria en Argentina. Revista mexicana de ciencias politicas y sociales, 61(227), pp. 349-378. https://doi.org/10.1016/S0185-1918(16)30032-0.

Castiñeira, A. R. (2020) La economía social y la recuperación del trabajo en Uruguay. REVESCO. Revista de Estudios Cooperativos, vol. 135, e69175. https://doi.org/10.5209/reve.69175.

Chanial, P., y Laville, J.-L. (2002) L'économie solidaire : une question politique. Mouvements, 1(19), pp. 11-20. https://doi.org/10.3917/mouv.019.0011. 
Chaves, R., y Demoustier, D. (2013) The Emergence of the Social Economy in Public Policy: An International Analysis (P. Lang (ed.)). Centre international de recherches et d'information sur l'économie collective.

Chaves, R., y Gallego, J. R. (2020) Transformative Policies for the Social and Solidarity Economy: The New Generation of Public Policies Fostering the Social Economy in Order to Achieve Sustainable Development Goals. The European and Spanish Cases. Sustainability, 12(10), p. 4059. https://doi.org/10.3390/su12104059.

Chaves, R., y Monzón, J. L. (2012) Beyond the crisis: the social economy, prop of a new model of sustainable economic development. Service Business, 6(1), pp. 5-26. https://doi.org/10.1007/s11628-011-0125-7.

Chaves, R., y Monzón, J. L. (2018) La economía social ante los paradigmas económicos emergentes: innovación social, economía colaborativa, economía circular, responsabilidad social empresarial, economía del bien común, empresa social y economía solidaria. CIRIEC-España, Revista de Economía Pública, Social y Cooperativa, № 93 , p. 5. https://doi.org/10.7203/ciriec-e.93.12901.

Chaves, R., Monzón, J. L., de Uralde, J. M. P., y Radrigán, M. (2013) La economía social en clave internacional. Cuantificación, reconocimiento institucional y visibilidad social en Europa, Iberoamérica y Norte de África. REVESCO. Revista de Estudios Cooperativos, $\quad \mathrm{N}^{\mathrm{o}} \quad 112, \quad \mathrm{pp} . \quad 122-150$. https://doi.org/10.5209/rev_reve.2013.v112.43069.

Chaves, R., y Savall, T. (2014) La insuficiencia de las actuales políticas de fomento de cooperativas y sociedades laborales frente a la crisis en España. REVESCO. Revista de Estudios Cooperativos, Tercer Cuatrimestre, $\mathrm{N}^{\mathrm{o}} 113$, pp. 61-91. https://doi.org/10.5209/rev_reve.2014.v113.43383.

Cid, B., Araya, E. A. L., Saravia, P., Vanhulst, J., Carroza, N., y Sandoval, D. (2019) Mapping social economy discourses in Chile. International Journal of Social Economics, 47(1), pp. 1-15. https://doi.org/10.1108/ijse-122018-0672.

Cole, G. D. H. (2018) A Century of Co Operation. Franklin Classics Trade Press. https://books.google.com.co/books/about/A_Century_of_Co_Operation.html?id=bwrXwgEACAAJ\&redir_esc=y.

Coraggio, J. L. (2011) ECONOMÍA SOCIAL Y SOLIDARIA. El trabajo antes que el capital (Alberto Acosta y (ed.)). Ediciones Abya-Yala Quito-Ecuador. https://www.coraggioeconomia.org/jlc/archivos\%20para\%20descargar/economiasocial.pdf.

Coraggio, J. L. (2013) Las tres corrientes de pensamiento y acción dentro del campo de la Economía Social y Solidaria. Revista Brasileira de Estudos Urbanos e Regionais, 15(2), 11. https://doi.org/10.22296/2317-1529.2013v15n2p11.

Dacheux, E., y Goujon, D. (2018) Principes d'économie solidaire. Revue internationale de l'économie sociale. https://hal.archives-ouvertes.fr/hal-02117563/.

Da Ros, G. S. (2007) Economía solidaria: aspectos teóricos y experiencias. uniRcoop, 5(1), pp. 9-27. https://www.socioeco.org/bdf fiche-document-3774_es.html.

Davila, M. R., Prieto, A. V., Blanco, L., Roa, E., Caceres, L. S., y Vargas, L. A. (2018) Características de la economía solidaria colombiana. Aproximaciones a las corrientes influyentes en Colombia. CIRIEC-España, Revista de Economía Pública, Social y Cooperativa, No 93, pp. 85-113. https://doi.org/10.7203/CIRIEC-E.93.10327.

Defourny, J. (1992) Economie sociale: entre économie capitaliste et économie publique. De Boeck. https://books.google.com/books/about/Economie_sociale.html?hl=yid=lF-2AAAAIAAJ.

Defourny, J., y Nyssens, M. (2008) Social enterprise in Europe: recent trends and developments. Social Enterprise Journal, Vol. 4, No 3, pp. 202-228. https://doi.org/10.1108/17508610810922703.

Defourny, J., y Nyssens, M. (2010) Conceptions of Social Enterprise and Social Entrepreneurship in Europe and the United States: Convergences and Divergences. Journal of Social Entrepreneurship, 1(1), pp. 32-53. https://doi.org/10.1080/19420670903442053.

Defourny, J., y Nyssens, M. (2021) Social Enterprise in Central and Eastern Europe: Theory, Models and Practice. Routledge. $\quad$ https://www.routledge.com/Social-Enterprise-in-Central-and-Eastern-Europe-Theory-Models-andPractice/Defourny-Nyssens/p/book/9780367342197.

Demiroz, F., y Haase, T. W. (2019) The concept of resilience: a bibliometric analysis of the emergency and disaster management literature. Local Government Studies, $45(3), \quad$ pp. $308-327$. https://doi.org/10.1080/03003930.2018.1541796.

DiMaggio, P. J., y Powell, W. W. (1983) The Iron Cage Revisited: Institutional Isomorphism and Collective Rationality in Organizational Fields. American Sociological Review, 48(2), p. 147. https://doi.org/10.2307/2095101.

Ding, Y., Yan, E., Frazho, A., y Caverlee, J. (2009) PageRank for ranking authors in co-citation networks. Journal of the American Society for Information Science. American Society for Information Science, 60(11), pp. $2229-2243$. https://doi.org/10.1002/asi.21171.

Duque, P., y Cervantes, L. S. (2019) Responsabilidad Social Universitaria: una revisión sistemática y análisis bibliométrico. Estudios Gerenciales, $35 \quad$ (153 Oct-Dic 2019$), \quad$ pp. $451-464$. https://doi.org/10.18046/j.estger.2019.153.3389.

Duque, P., Meza, O., Zapata, G., y Giraldo, J. (2021) Internacionalización de empresas latinas: evolución y tendencias. ECONÓMICAS CUC, 42(1). https://doi.org/10.17981/econcuc.42.1.2021.Org.1.

Duque, P., Samboni, V., Castro, M., Montoya, L. A., y Montoya, I. A. (2020) Neuromarketing: Its current status and research perspectives. Estudios Gerenciales, 36(157). https://doi.org/10.18046/j.estger.2020.157.3890.

Echchakoui, S. (2020) Why and how to merge Scopus and Web of Science during bibliometric analysis: the case of sales force literature from 1912 to 2019. Journal of Marketing Analytics, 8(3), pp. 165-184. https://link.springer.com/article/10.1057/s41270-020-00081-9. 
Espada, J. S., López, S. M., Durán, P. B., y de las Vacas, G. L. P. (2018) Educación y formación en emprendimiento social: características y creación de valor social sostenible en proyectos de emprendimiento social. REVESCO. Revista de Estudios Cooperativos, Tercer Cuatrimestre, No 129, pp. 16-38. https://doi.org/10.5209/REVE.62492.

Evans, M., y Syrett, S. (2007) Generating Social Capital?: The Social Economy and Local Economic Development. European urban and regional studies, 14(1), pp. 55-74. https://doi.org/10.1177/0969776407072664.

Fajardo, G. I. (2012) El fomento de la «economía social» en la legislación española. REVESCO. Revista de Estudios Cooperativos, Primer Cuatrimestre, No 107, pp. 58-97. https://doi.org/10.5209/rev_REVE.2012.v107.38747.

Fajardo, G. I. (2018) La identificación de las empresas de economía social en España. Problemática jurídica. REVESCO. Revista de Estudios Cooperativos, Segundo Cuatrimestre, $\mathrm{N}^{\mathrm{o}} \quad 128, \quad \mathrm{pp} . \quad 99-126$. https://doi.org/10.5209/reve.60209.

Fajardo, G. I. (2011) El fomento de la economía social en la legislación española. En CIRIEC (Ed.), La economía social, pilar de un nuevo modelo de desarrollo económico sostenible (p. 178). Centro Internacional de Investigación e Información sobre la Economía Pública, Social y Cooperativa, CIRIEC-España. https://dialnet.unirioja.es/servlet/articulo?codigo=7682609.

Fajardo, G. I., y Maestre, R. (2009) La economía social en las leyes. CIRIEC-España. Revista de Economía Pública, Social y Cooperativa, 5-36. http://ciriec-revistajuridica.es/la-economia-social-en-las-leyes/.

Ferguson, G. (2018) The Social Economy in Bolivia: Indigeneity, Solidarity, and Alternatives to Capitalism. VOLUNTAS: International Journal of Voluntary and Nonprofit Organizations, 29(6), pp. 1233-1243. https://doi.org/10.1007/s11266-018-0013-z.

Fernández, G. J., López, M. M., y Sarria, P. J. (2020) Cooperative Entrepreneurship Model for Sustainable Development. Sustainability: Science Practice and Policy, 12(13), p. 5462. https://doi.org/10.3390/su12135462.

Fournier, V. (2008) Escaping from the economy: the politics of degrowth. International Journal of Sociology and Social Policy, Vol. 28, No 11/12, pp. 528-545. https://doi.org/10.1108/01443330810915233.

França Filho, G. C. de. (2002) Terceiro setor, economia social, economia solidária e economia popular: traçando fronteiras conceituais. 12(1), pp. 9-19. http://repositorio.ufba.br/ri/handle/ri/25741.

França Filho, G. C., y Laville, J.-L. (2004) Economia solidária: uma abordagem internacional. Da Ufrgs. https://www.socioeco.org/bdf_fiche-publication-506_es.html.

Freeman, L. C. (1977) A Set of Measures of Centrality Based on Betweenness. Sociometry, 40(1), p. 35. https://doi.org/10.2307/3033543.

Frisch, J. R. (2009) Economía social de mercado (F. Ecuador (ed.); Vol. 2). Flacso Ecuador. https://biblio.flacsoandes.edu.ec/shared/biblio_view.php?bibid=125976\&tab=opac.

Gibson-Graham, J. K. (2006) A Postcapitalist Politics. University of Minnesota Press,. https://www.upress.umn.edu/book-division/books/a-postcapitalist-politics.

Gonzáles, M. R. (2018) Aportes para una definición plural y en tensión de la economía social y solidaria: entre el esencialismo y el historicismo. Universidad Academia de Humanismo Cristiano.

Guadarrama, S. G. J. (2019) El modelo de fundaciones comunitarias en México : una aproximación desde la perspectiva de los bienes comunes. Cooperativismo y Desarrollo, 27(115). https://doi.org/10.16925/2382-4220.2019.02.07.

Guerra, P. (2007) ¿Cómo denominar a las experiencias económicas solidarias basadas en el trabajo? Diálogo entre académicos latinoamericanos acerca de la polémica conceptual. Otra Economía, 1(1-2), pp. 21-27. https://www.socioeco.org/bdf_fiche-document-3088_es.html.

Gurzki, H., y Woisetschläger, D. M. (2017) Mapping the luxury research landscape: A bibliometric citation analysis. Journal of business research, 77, pp. 147-166. https://doi.org/10.1016/j.jbusres.2016.11.009.

Hannan, M. T., y Freeman, J. (1977) The Population Ecology of Organizations. American Journal of Sociology, 82(5), pp. 929-964. https://doi.org/10.1086/226424.

Hansmann, H. (1980) The Role of Non-profit Enterprise. The Yale Law Journal Company, Inc. https://www.jstor.org/stable/796089.

Hernandez, J. E., Montoya, I., y Montoya, L. A. (2020) The tree of science of deliberate and emergent strategies. IIMB Management Review, 32(4), pp. 413-433. https://doi.org/10.1016/j.iimb.2020.12.004.

Hirsch, J. E. (2005) An index to quantify an individual's scientific research output. Proceedings of the National Academy of Sciences of the United States of America, 102(46), pp. 16569-16572. https://doi.org/10.1073/pnas.0507655102.

Hudon, M., y Huybrechts, B. (2017) From distant neighbours to bedmates: exploring the synergies between the social economy and sustainable development. Annals of Public and Cooperative Economics, 88(2), pp. 141-154. https://doi.org/10.1111/apce.12170.

Hudson, D. S. (2020) The economic, social and environmental impacts of COVID 19. COVID-19 and Travel. https://doi.org/10.23912/9781911635703-4429.

Kazeroony, H. (2014) Capitalism and the Social Relationship (K. H. y S.-S. A. (eds.)). Palgrave Macmillan. https://doi.org/10.1057/9781137325709.0006.

Kenworthy, L. (2020) Social Democratic Capitalism and the Good Society. Social Democratic Capitalism, $19-71$. https://doi.org/10.1093/oso/9780190064112.003.0002.

Kerlin, J. A. (2006) Social Enterprise in the United States and Europe: Understanding and Learning from the Differences. VOLUNTAS: International Journal of Voluntary and Nonprofit Organizations, 17(3), pp. $246-262$. https://doi.org/10.1007/s11266-006-9016-2. 
Kim, D., Cho, W., y Allen, B. (2020) Sustainability of social economy organizations (SEOs): An analysis of the conditions for surviving and thriving. The Social science journal, 30, pp. 1-17. https://doi.org/10.1080/03623319.2020.1799174.

Kontogeorgos, A., y Chatzitheodoridis, F. (2019) Workers or Investors? Investigating the Reciprocity Aspects among Greek Social Enterprises Members. En REVESCO. Revista de Estudios Cooperativos, Tercer Cuatrimestre, $\mathrm{N}^{\mathrm{o}} 132$, pp. 9-28. https://doi.org/10.5209/reve.64303.

Labrador, M., Alfonso, A., y Rivera, R. (2017) Enfoques sobre la economía social y solidaria. Cooperativismo y Desarrollo, 5(2), pp. 137-146. http://coodes.upr.edu.cu/index.php/coodes/article/view/182.

Laville, J.-L. (2004) El marco conceptual de la economía solidaria. Economía social y solidaria. Una visión europea. Altamira. https://www.socioeco.org/bdf_fiche-document-131_es.html.

Lee, S. (2020) Role of social and solidarity economy in localizing the sustainable development goals. En International Journal of Sustainable Development y World Ecology, Vol. 27, No $1, \quad$ pp. $65-71$. https://doi.org/10.1080/13504509.2019.1670274.

Levitt, T. (1973) The Third Sector: New Tactics for a Responsive Society. New York. AMACOM.

Loh, P., y Shear, B. (2015) Solidarity economy and community development: emerging cases in three Massachusetts cities. Community development, 46(3), pp. 244-260. https://doi.org/10.1080/15575330.2015.1021362.

Lucia, J. S., Giménez, A. F., y Rosanas, M. C. (2009) Medio siglo de Economía Social de Mercado. Revista de fomento social, 253(1), pp. 79-102. https://doi.org/10.32418/rfs.2009.253.2011.

Mair, J., y Martí, I. (2006) Social entrepreneurship research: A source of explanation, prediction, and delight. Journal of World Business, Vol. 41, No 1, pp. 36-44. https://doi.org/10.1016/j.jwb.2005.09.002.

Marier, B. T., Pellerin, R., y Cassivi, L. (2017) Project Planning and Control in Social and Solidarity Economy Organizations: A Literature Review. Procedia computer science, 121, pp. $692-698$. https://doi.org/10.1016/j.procs.2017.11.090.

McIntyre, R. (2018) The Development of Social Economy in France Since 1945. Forum for Social Economics, Vol. 47, No 2, pp. 253-261. https://doi.org/10.1080/07360932.2018.1451768.

Monna, V. (2017) Make the environment the (Next) Economy. The Design Journal, 20(sup1), S1836-S1851. https://doi.org/10.1080/14606925.2017.1352702.

Monteagudo, I. C., y Buendía, M. I. (2020) Political Activism as Driver of Cooperative Sector. VOLUNTAS: International Journal of Voluntary and Nonprofit Organizations, Vol. 31, $\mathrm{N}^{\mathrm{o}} \quad 3, \quad$ pp. $601-613$. https://doi.org/10.1007/s11266-020-00198-6.

Montolio, J. M. (2002) Economía social: concepto, contenido y significación en España. CIRIEC-España, Revista de Economía Pública, Social y Cooperativa, 42(1), pp. 5-31. https://www.redalyc.org/articulo.oa?id=17404201.

Monzón, J. L. (1989a) Las cooperativas de trabajo asociado en la literatura económica y en los hechos. Ministerio de Trabajo y Seguridad Social. Madrid. https://www.iberlibro.com/COOPERATIVAS-TRABAJO-ASOCIADOLITERATURA-ECONOMICA-HECHOS/892302134/bd.

Monzón, J. L. (2006) Economia Social y Conceptos afines: fronteras borrosas y ambigüedades del Tercer Sector. CIRIEC-España, Reivista de Economia Publica, Social y Cooperativa, 56, pp. 9-24. https://www.socioeco.org/bdf_fiche-document-662_es.html.

Monzón, J. L. (2013) Empresas sociales y economía social : perímetro y propues tas metodológicas para la medición de su i mpacto socioeconómico en la U.E. Revista de economía mundial, 35, pp. 151-163. http://hdl.handle.net/10272/7703.

Monzon, J. L., y Chaves, R. (2008) THE EUROPEAN SOCIAL ECONOMY: CONCEPT AND DIMENSIONS OF THE THIRD SECTOR. Annals of Public and Cooperative Economics, 79(3-4), pp. 549-577. https://doi.org/10.1111/j.1467-8292.2008.00370.x.

Monzón, J. L., y Chaves, R. (2012a) La Economía Social en la Unión Europea. Comité Económico y Social Europeo de la Unión Europea. https://doi.org/10.2864/19566.

Monzón, J. L., y Chaves, R. (2012b) The social economy in the European Union (European Economic and Social Committee (ed.)). CIRIEC. https://www.eesc.europa.eu/en.

Moulaert, F., y Ailenei, O. (2005) Social Economy, Third Sector and Solidarity Relations: A Conceptual Synthesis from History to Present. Urban studies, 42(11), pp. 2037-2053. https://doi.org/10.1080/00420980500279794.

Navarro, A. M., Climent, V. C., y Palacio, J. R. S. (2011) Emprendimiento social y empresas de inserción en España. Aplicación del método delphi para la determinación del perfil del emprendedor y las empresas sociales creadas por emprendedores. REVESCO. Revista de Estudios Cooperativos, Tercer Cuatrimestre, No 106, pp. $150-172$. https://doi.org/10.5209/rev_reve.2011.v106.37377.

Núñez, R. B. C., Bandeira, P., y Santero-Sánchez, R. (2020) Social Economy, Gender Equality at Work and the 2030 Agenda: Theory and Evidence from Spain. Sustainability: Science Practice and Policy, 12(12), p. 5192. https://doi.org/10.3390/su12125192.

Ohri, A. (2012) $R$ for Business Analytics. Springer Science y Business Media. https://play.google.com/store/books/details?id=D2Su4qomE4sC.

Page, L., Brin, S., Motwani, R., y Winograd, T. (1999) The PageRank Citation Ranking: Bringing Order to the Web. http://ilpubs.stanford.edu:8090/422/. 
Pavlovskaya, M., Borowiak, C., Safri, M., Healy, S., y Eletto, R. (2020) The Place of Common Bond: Can Credit Unions Make Place for Solidarity Economy? Annals of the American Association of Geographers, 110(4), pp. 12781299. https://doi.org/10.1080/24694452.2019.1685368.

Peredo, A. M., y McLean, M. (2006) Social entrepreneurship: A critical review of the concept. Journal of World Business, Vol. 41, № 1, pp. 56-65. https://doi.org/10.1016/j.jwb.2005.10.007.

Pérez, de M. J. C. (2015) Sobre el concepto de economía social y solidaria: aproximaciones desde Europa y América Latina. Universidad del Pais Vasco. https://www.redalyc.org/pdf/866/86641407006.pdf.

Pérez, J. C., y Etxezarreta, E. (2015) Sobre el concepto de economía social y solidaria: aproximaciones desde Europa y América Latina. Revista de economía mundial, 40, pp. https://dialnet.unirioja.es/servlet/articulo?codigo=5199917.

Périz, J. L. A. (2002) El Tercer Sector y Economía Social: marco teórico y situación social. Acciones e Investigaciones Sociales, 15(1), pp. 239-263. https://doi.org/10.26754/ojs_ais/ais.200215230.

Pérotin, V. (2006) Entry, exit, and the business cycle: Are cooperatives different? Journal of Comparative Economics, Vol. 34, No 2, pp. 295-316. https://doi.org/10.1016/i.jce.2006.03.002.

Pestoff, V., y Defourny, J. (2008) Images and concepts of the third sector in Europe - Emes. EMES - International Research Network. EMES Working Papers. https://emes.net/publications/working-papers/images-and-concepts-ofthe-third-sector-in-europe/.

Powell, W. W., y Steinberg, R. (2006) The Nonprofit Sector: A Research Handbook. Yale University Press. https://www.sup.org/books/title/?id=30371.

Predețeanu, D. D., Popescu, D., y Nicolae, V. (2019) Volunteering - An Efficient Collaborative Practice for the Local Communities Sustainability. Empirical Study. European Journal of Sustainable Development, Vol. 8, No 5, p. 302. https://doi.org/10.14207/ejsd.2019.v8n5p302.

Presta, S. R. (2020) Economía social y solidaria, trabajo y «don de sí mismo». Cooperativismo y Desarrollo, 28(116), pp. 1-20. https://revistas.ucc.edu.co/index.php/co/article/view/3132.

Reis, H. (2014) A atuação da Economia Social numa lógica de proximidade: oportunidades e desafios. Investigação $e$ Intervenção em Recursos Humanos, № 1. https://doi.org/10.26537/iirh.v0i1.1924.

Resico, M. F. (2009) Economía social de mercado : una opción económica para Latinoamérica. Diálogo Político, 26(1), pp. 133-151. https://repositorio.uca.edu.ar/handle/123456789/2327.

Rey, M. A., Ribeiro, S. D., y Palacios, M. D. (2016) A bibliometric analysis of social entrepreneurship. Journal of business research, 69(5), pp. 1651-1655. https://doi.org/10.1016/j.jbusres.2015.10.033.

Ríos, M. S., Perdiguer, M. F., y Solé, T. T. (2014) Un análisis del comportamiento cíclico de las cooperativas y sociedades laborales españolas y su relación con la actividad económica. REVESCO. Revista de Estudios Cooperativos, Segundo Cuatrimestre, No 115, pp. 7-29. https://doi.org/10.5209/rev reve.2014.v115.45279.

Robledo, S., Osorio, G., y Lopez, C. (2014) Networking en pequeña empresa: una revisión bibliográfica utilizando la $\begin{array}{lllll}\text { teoria } & \text { grafos. } & \text { Revista } & \text { pínculos, } & \text { 6-16. }\end{array}$ https://revistas.udistrital.edu.co/index.php/vinculos/article/view/9664.

Rubel, M. (1977) Allemagne et coopération. Archives Internationales de Sociologie de la.

Saguier, M., y Brent, Z. (2017) Social and Solidarity Economy in South American regional governance. Global Social Policy, 17(3), pp. 259-278. https://doi.org/10.1177/1468018116686921.

Sahakian, M. D., y Dunand, C. (2015) The social and solidarity economy towards greater «sustainability»: learning across contexts and cultures, from Geneva to Manila. Community development journal, 50(3), pp. $403-417$. https://doi.org/10.1093/cdj/bsu054.

Salamon, L. M., y Anheier, H. K. (1997) Defining the Nonprofit Sector: A Cross-national Analysis. Manchester University Press.

https://books.google.com/books/about/Defining the_Nonprofit_Sector.html?hl=yid=ffY_NY3EpYcC.

Salamon, L. M., y Wojciech Sokolowski, S. (2016) Beyond Nonprofits: Re-conceptualizing the Third Sector. VOLUNTAS: International Journal of Voluntary and Nonprofit Organizations, 27(4), pp. 1515-1545. https://doi.org/10.1007/s11266-016-9726-z.

Sala, R. M., Farré, P. M., y Torres, S. T. (2017) Immigrants' Employment in Spanish Cooperatives: Outcomes in Relation to the Business Cycle. VOLUNTAS: International Journal of Voluntary and Nonprofit Organizations, 28(5), pp. 1940-1961. https://doi.org/10.1007/s11266-016-9817-X.

Salazar, D. F. T., Álvarez, J. M. R., Garcés, J. J. H., y Duque, P. (2020) Riesgos en las Microfinanzas: Una revisión y análisis Bibliométrico*. Interfaces, http://www.unilibrecucuta.edu.co/ojs/index.php/ingenieria/article/view/484.

Schneider, F., Kallis, G., y Martinez-Alier, J. (2010) Crisis or opportunity? Economic degrowth for social equity and ecological sustainability. Introduction to this special issue. Journal of Cleaner Production, Vol. 18, No 6, pp. 511518. https://doi.org/10.1016/j.jclepro.2010.01.014.

Scott, S. (2015) Social and Solidarity Economy: Beyond the Fringe. Eutopía - Revista de Desarrollo Económico Territorial, 7, p. 165. https://doi.org/10.17141/eutopia.7.2015.1755.

Singer, P. (1997) Economia solidária: geração de renda e alternativa ao liberalismo. Proposta, 72, pp. 5-13. http://www.ijsn.es.gov.br/bibliotecaonline/Record/3245.

Smith, G. (2005) Green Citizenship and the Social Economy. Environmental politics, 14(2), pp. $273-289$. https://doi.org/10.1080/09644010500055175. 
Sonnino, R., y Griggs, T. C. (2013) A resilient social economy? Insights from the community food sector in the UK. Entrepreneurship and Regional Development, 25(3-4), pp. 272-292. https://doi.org/10.1080/08985626.2012.710268.

Stiglitz, J. E. (2009) Moving beyond Market Fundamentalism to a More Balanced Economy. Annals of Public and Cooperative Economics, 80(3), pp. 345-360. https://doi.org/10.7916/D8988HV1.

Tani, M., Papaluca, O., y Sasso, P. (2018) The System Thinking Perspective in the Open-Innovation Research: A Systematic Review. Journal of Open Innovation: Technology, Market, and Complexity, 4(3), p. 38. https://doi.org/10.3390/joitmc4030038.

Tomás, C. (1997) The prospects for the social economy in a changing world. Annals of Public and Cooperative Economics, 68(2), pp. 247-279. https://doi.org/10.1111/1467-8292.00045.

Valencia, H. D. S., Robledo, S., Pinilla, R., Duque, M. N. D., y Gerard, O. T. (2020) SAP Algorithm for Citation Analysis: An improvement to Tree of Science. Ingeniería e Investigación, 40(1), pp. 45-49. https://doi.org/10.15446/ing.investig.v40n1.77718.

Vera, B. M. A., Thelwall, M., y Kousha, K. (2019) Web of Science and Scopus language coverage. Scientometrics, 121(3), pp. 1803-1813. https://doi.org/10.1007/s11192-019-03264-z.

Villalba, E. U., y Pérez, J. C. (2019) La economía social y solidaria como vía para el buen vivir. Revista iberoamericana de estudios de desarrollo $=$ Iberoamerican journal of development studies, 8(1). https://doi.org/10.26754/ojs_ried/ijds.338.

Wallis, W. D. (2007) A Beginner's Guide to Graph Theory (Springer (ed.)). Birkhäuser Boston. https://doi.org/10.1007/978-0-8176-4580-9.

Weisbrod, B. A. (1986) Toward a Theory of the Voluntary Non-profit Sector in a Three-sector Economy. En E. RoseAckerman (Ed.), The Economics of Nonprofit Institutions. Oxford University Press. https://www.semanticscholar.org/paper/Toward-a-Theory-of-the-Voluntary-Nonprofit-Sector-aWeisbrod/395320d5d76e734e5682a84f5c5c0f50e9bbb1b8.

Weisbrod, B. A. (2009) The Nonprofit Economy. Harvard University Press. https://play.google.com/store/books/details?id=hguMjSfF4W4C.

Yan, E., Ding, Y., y Sugimoto, C. R. (2010) P-Rank: An indicator measuring prestige in heterogeneous scholarly networks. Journal of the American Society for Information Science. American Society for Information Science, 56. https://doi.org/10.1002/asi.21461.

Yang, S., Keller, F. B., y Zheng, L. (2016) Social Network Analysis: Methods and Examples. SAGE Publications. https://books.google.com/books/about/Social_Network_Analysis.html?hl=yid=2ZNIDQAAQBAJ.

Zhang, J., y Luo, Y. (2017) Degree Centrality, Betweenness Centrality, and Closeness Centrality in Social Network. Proceedings of the 2017 2nd International Conference on Modelling, Simulation and Applied Mathematics (MSAM2017). https://doi.org/10.2991/msam-17.2017.68.

Zhu, J., y Liu, W. (2020) A tale of two databases: the use of Web of Science and Scopus in academic papers. Scientometrics, 123(1), pp. 321-335. https://doi.org/10.1007/s11192-020-03387-8.

Zupic, I., y Čater, T. (2015) Bibliometric Methods in Management and Organization. Organizational Research Methods, 18(3), pp. 429-472. https://doi.org/10.1177/1094428114562629.

Zuschke, N. (2020) An analysis of process-tracing research on consumer decision-making. Journal of business research, 111, pp. 305-320. https://doi.org/10.1016/j.jbusres.2019.01.028. 